\title{
Numerical Simulations of the South American Low Level Jet in Two Episodes of MCSs: Sensitivity to PBL and Convective Parameterization Schemes
}

\author{
Daniel Caetano Santos and Ernani de Lima Nascimento \\ Departamento de Física, Universidade Federal de Santa Maria, 97119-900 Santa Maria, RS, Brazil \\ Correspondence should be addressed to Daniel Caetano Santos; danielcae@ufsm.br
}

Received 4 July 2016; Revised 26 August 2016; Accepted 1 September 2016

Academic Editor: Enrico Ferrero

Copyright (C) 2016 D. C. Santos and E. L. Nascimento. This is an open access article distributed under the Creative Commons Attribution License, which permits unrestricted use, distribution, and reproduction in any medium, provided the original work is properly cited.

\begin{abstract}
The sensitivity of numerical simulations of the low level jet stream (LLJS) in South America to the choice of parameterization schemes for the planetary boundary layer (PBL) and for cumulus convection using the Advanced Research core of the Weather Research and Forecast (WRF) model was assessed for two cases in which the development of Mesoscale Convective Systems (MCSs) was observed in the La Plata Basin at the exit of the LLJS. The MCSs developed under distinct synoptic forcing. Overall, the general area over the La Plata Basin where the wind profiles met LLJS criteria was larger in the situation with stronger frontal forcing. Regarding the impact of the choice of the PBL parameterization scheme upon the simulated LLJS, the nonlocal Yonsei University (YSU) scheme displayed slightly better results for most simulations regardless of the cumulus parameterization scheme utilized. In fact, the characterization of the LLJS in the simulations exhibited no significant sensitivity to the choice of the cumulus parameterization. In situations under stronger [weaker] frontal forcing, less [more] dispersion among the simulations was found regarding the identification of the LLJS.
\end{abstract}

\section{Introduction}

The South American low level jet stream (SALLJS), observed east of the Andes Mountain Range, is the main atmospheric mechanism responsible for the meridional moisture transport from the Amazon Basin to the subtropics of South America south of $20^{\circ} \mathrm{S}$ [1]. The SALLJS plays a crucial role in supplying moisture to precipitating systems in the $\mathrm{La}$ Plata Basin (Figure 1), particularly in episodes of Mesoscale Convective Systems (MCSs) $[2,3]$.

Utilizing data from the National Centers for Environmental Prediction and National Center for Atmospheric Research (NCEP-NCAR) Reanalysis, Marengo et al. [4] showed that, overall, the SALLJS can occur at any time of the year. However, over Paraguay and southern Brazil, located in the southern half of the geographic domain where it is usually observed, the SALLJS is more frequently detected during the cold season. Salio et al. [3] discussed the strong relation between the development of MCSs in the La Plata Basin and the occurrence of SALLJS, especially during the warm season. Similar relation is also found for the Central Plains of the United States of America (USA) (e.g., [5]). Saulo et al. [2] also addressed the connection between the exit region of the SALLJS and the triggering of deep moist convection. They showed that the development of deep convection is favored by the low level warm and most advection induced by the SALLJS. In turn, the strong latent heating accompanying the convective activity leads to geopotential height falls in the lower troposphere over the La Plata Basin which enhances northerly winds and low level convergence at the SALLJS exit region, leading to further convective development and increased longevity of the MCSs.

Evidently, the correct representation of the magnitude and location of the SALLJS by mesoscale numerical models is crucial to the simulation of convective systems which affect the subtropical sector of South America. Planetary boundary layer (PBL) mechanisms that control the formation of nocturnal low level wind maxima (or simply low level jets 


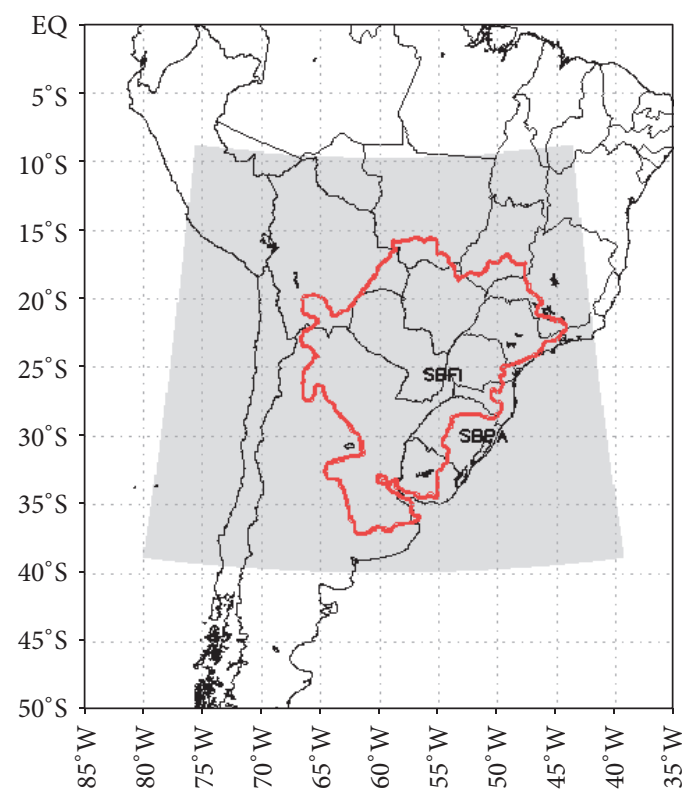

FIGURE 1: Geographic extent of the La Plata Basin (red contour) and the model domain utilized in the ARW-WRF simulations (grey shading). Four-letter codes indicate the location of Foz do Iguaçu (SBFI) and Porto Alegre (SBPA) upper air meteorological stations.

(LLJs)) are among the processes that influence the behavior of low level jet streams worldwide (e.g., [6]). In the specific case of the subtropical South America, Marengo et al. [4] found a diurnal cycle in the SALLJS activity, with the most intense magnitudes being more frequent during the night or in the early morning hours. Vanderwende et al. [7] utilized wind profiles observed during the Crop Wind Energy Experiment (CWEX) in the USA to assess the numerical simulations of LLJs with the Weather Research and Forecast model (WRF model, [8]). In general, they found strong sensitivity in the simulation of the LLJ to the data source employed to provide the initial conditions; when considering only the strongest LLJs, the greatest sensitivity reported by Vanderwende et al. [7] was with respect to the choice of PBL parameterization scheme, with the local schemes yielding the best results.

$\mathrm{Hu}$ et al. [9] compared the performances of three distinct PBL parameterization schemes in the WRF model and found that the local Mellor-Yamada [nonlocal Yonsei University] scheme overestimated [underestimated] the intensity of the nocturnal LLJ in the first $500 \mathrm{~m}$ of the PBL.

Given the sensitivity of numerical simulations of atmospheric phenomena to the parameterization schemes of subgrid processes and the case-to-case variability of the degree of such sensitivity, it is difficult to identify a single set of most efficient physical schemes for the simulation of a broad range of atmospheric phenomena $[10,11]$. On the other hand, such sensitivity represents an opportunity to the generation of a physics-based ensemble of simulations with the utilization of different parameterization schemes with the same numerical model.

Using the WRF model, this study assesses the sensitivity of the numerical simulation of the SALLJS to the choice of parameterization schemes for the PBL and for cumulus
TABLE 1: Set of simulations with the ARW-WRF model combining distinct physical parameterization schemes.

\begin{tabular}{lcc}
\hline Simulation & Boundary layer scheme & $\begin{array}{c}\text { Cumulus convection } \\
\text { scheme }\end{array}$ \\
\hline YSU-BMJ & Yonsei University [12] & $\begin{array}{c}\text { Betts-Miller-Janjić } \\
{[13,14]}\end{array}$ \\
MYJ-BMJ & Mellor-Yamada-Janjić [13] & Betts-Miller-Janjić \\
YSU-KF & Yonsei University & Kain-Fritsch [15] \\
MYJ-KF & Mellor-Yamada-Janjić & Kain-Fritsch \\
YSU-GF & Yonsei University & Grell-Freitas [16] \\
MYJ-GF & Mellor-Yamada-Janjić & Grell-Freitas \\
\hline
\end{tabular}

convection for two cases in which the development of MCSs in the La Plata Basin was observed.

\section{Methodology and Data}

Two sets of six numerical simulations each were performed for situations in which MCSs were observed over the La Plata Basin using the Advanced Research core of the Weather Research and Forecast (ARW-WRF) model, version 3.5.1. All simulations employed a numerical domain of $303 \times 284$ points with $12 \mathrm{~km}$ horizontal grid spacing and 33 vertical sigma levels covering the La Plata Basin (Figure 1). Each simulation was $48 \mathrm{hr}$ long and utilized a distinct combination of PBL and convective parameterization schemes, as described in Table 1. These physical schemes were chosen because they are frequently utilized in mesoscale numerical studies. In particular, the choice of MYJ and YSU PBL schemes was motivated by the interest in evaluating the impact of closure assumptions (local versus nonlocal) in the simulations. 


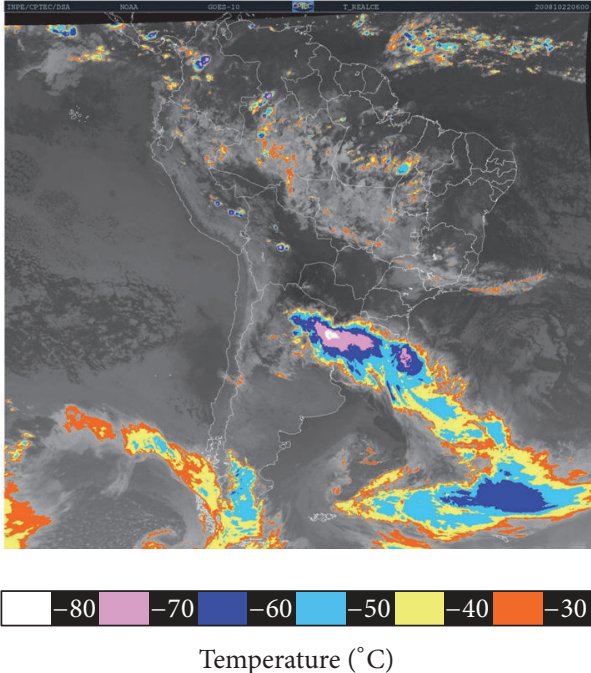

(a)
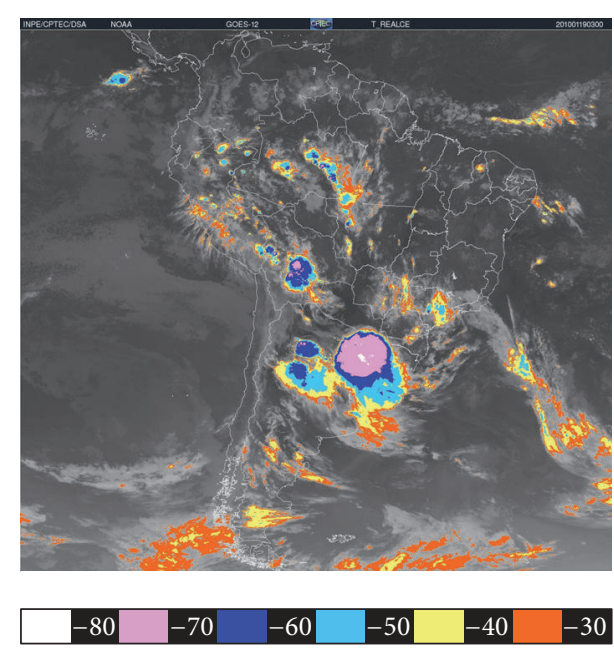

Temperature $\left({ }^{\circ} \mathrm{C}\right)$

(b)

FIGURE 2: Enhanced thermal infrared imagery from the Geostationary Operational Environmental Satellite (GOES) during the mature stage of the MCSs: (a) GOES-10 at 0600 UTC 22 October 2008; (b) GOES-12 at 0300 UTC 19 January 2010. Colored shading scale indicates brightness temperatures in Celsius (source: National Oceanic and Atmospheric Administration (NOAA, USA) and Environmental Satellite Division of the National Institute for Space Research (DSA-INPE, Brazil)).

Two cases of warm season nocturnal MCSs which developed at the exit region of the SALLJ were selected for the simulations. The first case occurred from the late night hours of 21 October 2008 to the morning hours of 22 October 2008; the second case was observed from the night of 18 January 2010 to the morning of 19 January 2010. These two MCS events were chosen because they represent typical examples of MCSs occurring under different synoptic settings (strong versus weak forcing) in the La Plata Basin, both in the presence of the SALLJS.

Figures 2(a) and 2(b) show, respectively, the GOES-10 and GOES-12 enhanced thermal infrared imagery over South America during the mature stages of the two corresponding MCSs. Because the main focus of this study is on the numerical representation of the SALLJ prior to and during the MCSs, the 48-hour simulations were initiated at $12 \mathrm{Z}$ of 20 October 2008 for the first case and at $12 \mathrm{Z}$ of 17 January 2010 for the second case, roughly 36 hours prior to the mature stage of the MCSs. Data from the NCEP Climate Forecast System Reanalysis (CFSR; [17]) were used as initial and boundary conditions for the simulations, with the lateral boundary conditions being updated at 6-hour intervals. Table 2 provides further information about the numerical simulations.

Two approaches were followed to analyze the sensitivity of the simulations to the choice of PBL and convective parameterization schemes. First, the simulated profiles of the lower troposphere were compared to the corresponding observed profiles obtained from radiosondes launched from two operational upper air stations located in southern Brazil, namely, Foz do Iguaçu (SBFI; $25.52^{\circ} \mathrm{S}, 54.58^{\circ} \mathrm{W}, 180 \mathrm{~m}$ ) and Porto Alegre (SBPA; $\left.30^{\circ} \mathrm{S}, 51.18^{\circ} \mathrm{W}, 3 \mathrm{~m}\right)$. Their locations are indicated in Figure 1. The comparison was conducted at the
TABLE 2: Additional information regarding choices of parameterization schemes used in the ARW-WRF simulations listed in Table 1.

\begin{tabular}{lc}
\hline Parameterization & Scheme \\
\hline Cloud microphysics & Lin et al. [18] \\
Radiation: long wave & RRTM \\
Radiation: short wave & Dudhia \\
Soil & NOAH \\
\hline
\end{tabular}

24th hour of the model integration, which means at $12 \mathrm{Z}$ of 21 October 2008 for the first case and at $12 Z$ of 18 January 2010 for the second case, around 12 hours prior to the initiation of the MCSs. The model grid point nearest to the corresponding observation site was utilized to perform this verification.

This first approach included the characterization, in both the simulated and observed profiles, of LLJS conditions based upon speed criterion 1 established by Bonner [19] which states that (a) the maximum wind speed below $3 \mathrm{~km}$ AGL must equal or exceed $12 \mathrm{~m} / \mathrm{s}$ and (b) a wind speed difference of at least $6 \mathrm{~m} / \mathrm{s}$ must exist between such maximum speed and the lowest speed aloft within the same $3 \mathrm{~km}$ layer. To better characterize the presence of the SALLJ, one additional criterion was adopted, in which the meridional wind component must be negative (i.e., northerly) and larger, in magnitude, than the zonal component between $1500 \mathrm{~m}$ and $3000 \mathrm{~m}$, which is the same Bonner modified criterion used by Marengo et al. [4]. Moreover, the simulated profiles of potential temperature $(\theta)$, moisture (water vapor mixing ratio, qv), and winds in the first $3 \mathrm{~km}$ were also compared to the observed profiles at SBFI and SBPA. To that end, the variables in the simulated profiles were vertically interpolated from the model sigma levels to the levels for which the corresponding observation 


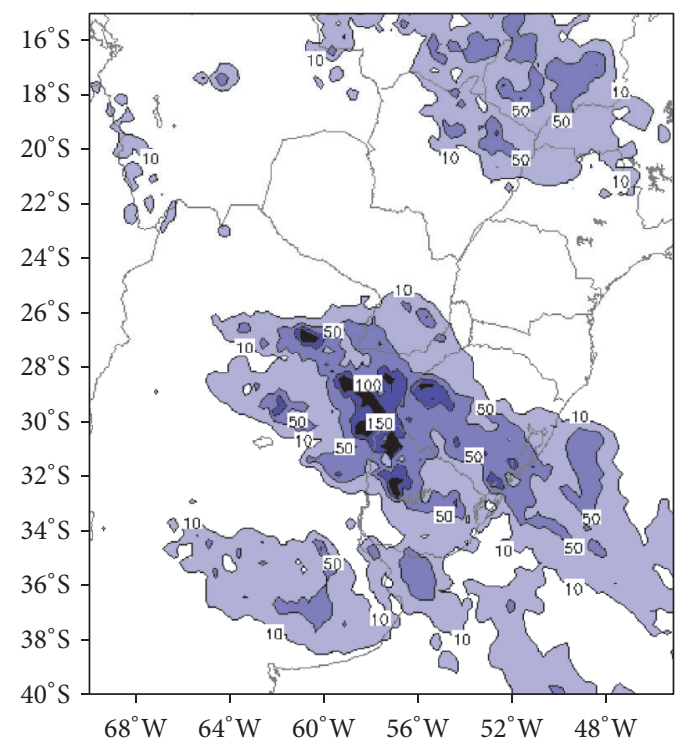

(a)

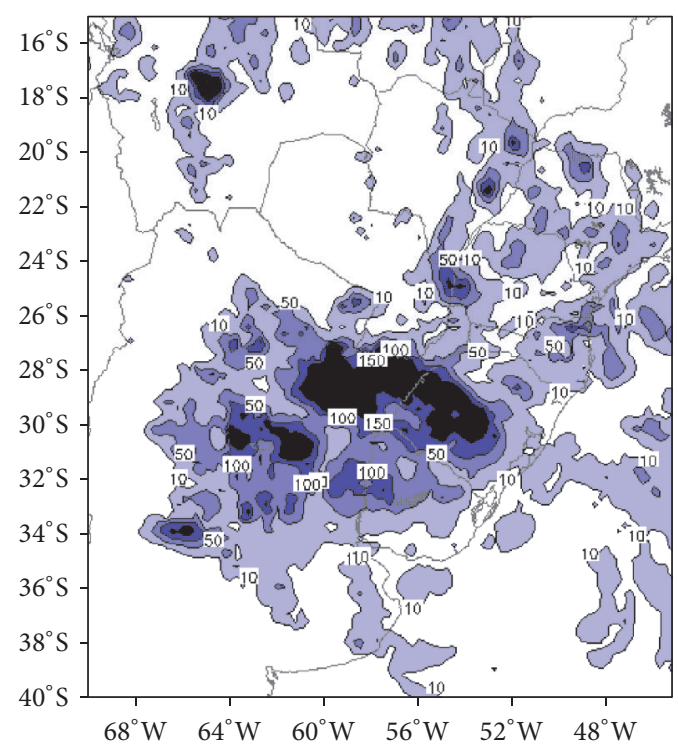

(b)

Figure 3: Satellite-estimated $48 \mathrm{hr}$ rainfall accumulation (in mm) over the La Plata Basin valid at (a) $1200 \mathrm{Z} 22$ October 2008 and (b) $1200 \mathrm{Z}$ 20 January 2010. Source: Climate Prediction Center merged microwave (http://rda.ucar.edu/).

is available from the sounding. The following linear weighted interpolation function was used:

$$
\begin{aligned}
D(h)= & \left\{d\left[h_{1}\right] *\left[1-\frac{\left(h-h_{1}\right)}{\left(h_{2}-h_{1}\right)}\right]\right\} \\
& +\left\{d\left[h_{2}\right] *\left[1-\frac{\left(h_{2}-h\right)}{\left(h_{2}-h_{1}\right)}\right]\right\},
\end{aligned}
$$

where $D(h)$ is the interpolated value at the observed level $h$ and $d[h]$ is the simulated value at the two neighboring sigma levels $h_{1}$ and $h_{2}$.

To assess the simulated vertical profiles of $\theta$, qv, and wind speed with respect to the corresponding profiles obtained from SBFI and SBPA, the Pearson correlation coefficient, root mean square error (RMSE), and bias [20] were computed at those two locations.

A second approach for evaluating the model sensitivity in representing the LLJS with respect to the choice of PBL and convective parameterization schemes consisted in determining, for every model grid point, the percentage of simulations in which the LLJS was characterized. This analysis was performed in 12-hour intervals (00Z and 12Z) of the model integration, with results being presented in the form of maps that display the spatial distribution of percentage number of simulations with LLJS identification.

For comparison, CFSR data and actual upper air observations (where available) are also utilized to assess the spatial distribution and extent of the sectors, where the LLJS was characterized.

\section{Results}

3.1. General Synoptic Overview of the MCS Episodes. The selected MCSs were both associated with high rainfall accumulation (reaching $150 \mathrm{~mm}$ in $48 \mathrm{~h}$ ) in the La Plata Basin as shown in Figure 3. However, the MCSs occurred under distinct synoptic forcing, as described below.

3.1.1. Case 1: 21 October 2008. The 21 October 2008 MCS event developed over north-central Argentina in association with a migratory baroclinic system (Figure 4(a)), with the combined manifestation of cyclogenesis off the Patagonian coast (just east of a $500 \mathrm{hPa}$ trough) and the intensification of the Northwestern Argentinean Low (NAL; [21]) over the Andes foothills (Figure 4(b)). The MCS initiation occurred at the equatorial entrance of the polar jet streak (Figure 4(d)), while the surface frontal trough was dynamically coupled with the inverted trough associated with the NAL, forming a col point roughly over the southeastern Uruguayan coast (Figure 4(e)). The frontogenetic function confirms the baroclinic nature of the NW-to-SE-oriented surface front over north-central Argentina (Figure 4(f)) along which the MCS initiation took place. Moderate-to-strong low level moisture flux was in place over the warm sector in northern Argentina in association with $850 \mathrm{hPa}$ northerly winds (Figures $4(\mathrm{~b})$, $4(\mathrm{e})$, and $4(\mathrm{~h})$ ). This event was chosen to characterize a MCS development under strong frontal forcing.

3.1.2. Case 2: 19 January 2010. Figure 5 depicts the general synoptic evolution during the 19 January 2010 MCS. This event developed over northern Argentina just east of a migratory $500 \mathrm{hPa}$ trough (Figures 5(a), 5(d), and 5(g)). At 


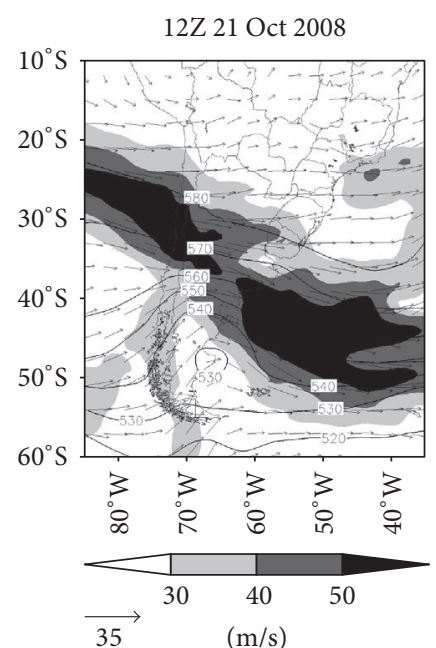

(a)

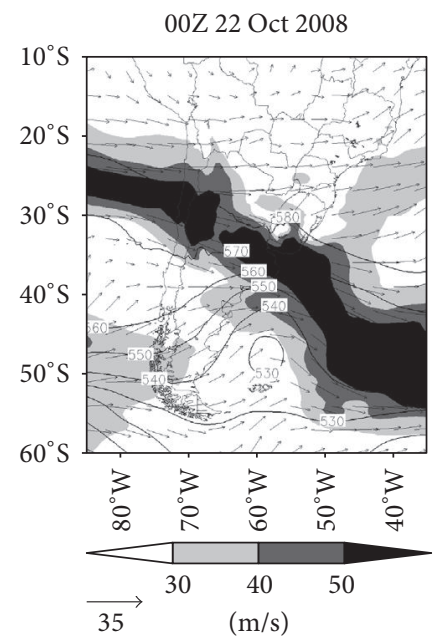

(d)

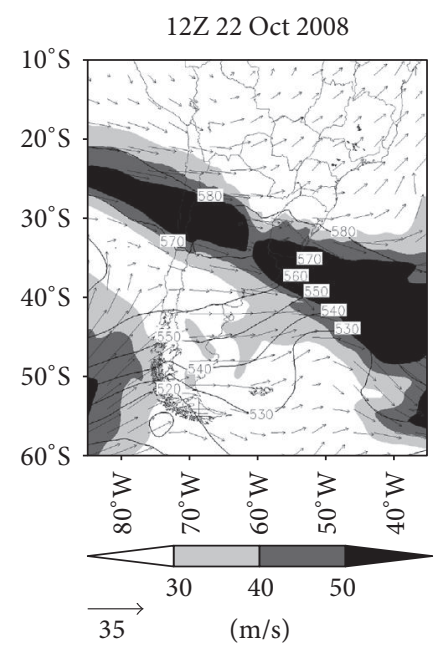

(g)

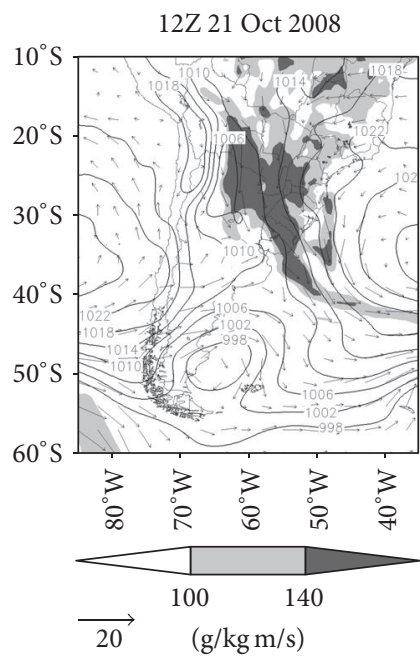

(b)

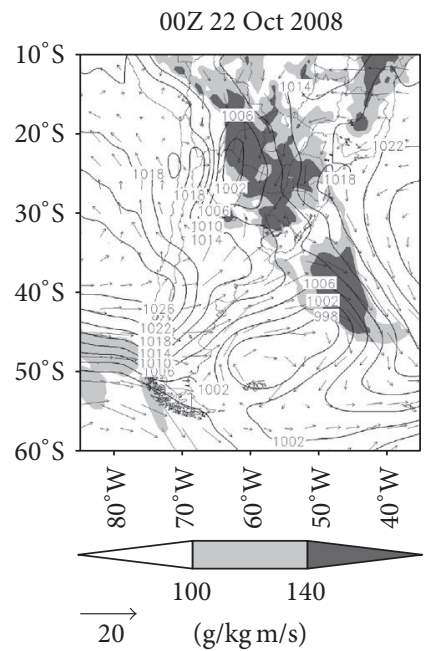

(e)

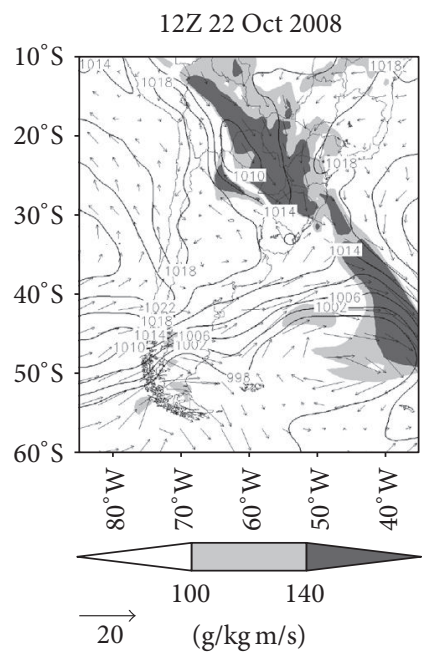

(h)

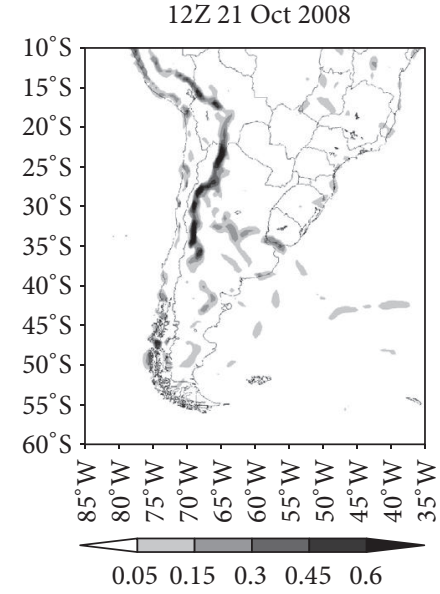

(c)

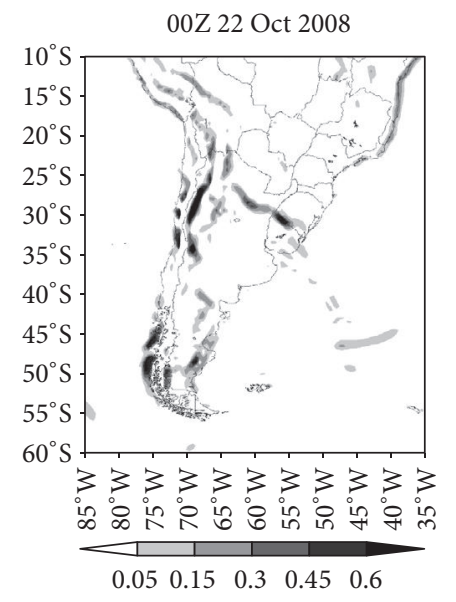

(f)

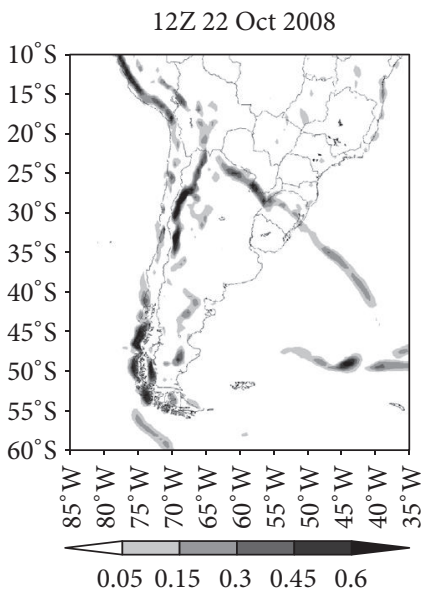

(i)

Figure 4: Atmospheric fields from NCEP CSF Reanalysis valid at 12Z 21 October 2008 ((a)-(c)), 00Z 22 October 2008 ((d)-(f)), and $12 Z 22$ October 2008 ((g)-(i)). (a), (d), and (g): $500 \mathrm{hPa}$ geopotential heights (black contours, in dam), $200 \mathrm{hPa}$ winds (vectors, in $\mathrm{m} \mathrm{s}^{-1}$; reference vector indicated in the bottom of (a), (d), and ( $\mathrm{g})$ ), and wind speed (grey shading, in $\mathrm{m} \mathrm{s}^{-1}$; shading scale provided at the bottom of (a), (d), and (g)). (b), (e), and (h): mean sea level pressure (black contours, in hPa), $850 \mathrm{hPa}$ winds (vectors, in $\mathrm{m} \mathrm{s}^{-1}$; reference vector indicated at the bottom of (b), (e), and (h)), and moisture flux (grey shading, in $\mathrm{g} \mathrm{kg}^{-1} \mathrm{~m} \mathrm{~s}^{-1}$; shading scale provided at the bottom of (b), (e), and (h)). (c), (f), and (i): surface frontogenetic function, only where it is equal to or greater than $0.05 \times 10^{-8} \mathrm{~K} \mathrm{~m}^{-1} \mathrm{~s}^{-1}$ (see shading scale provided at the bottom of (c), (f), and (i)). 


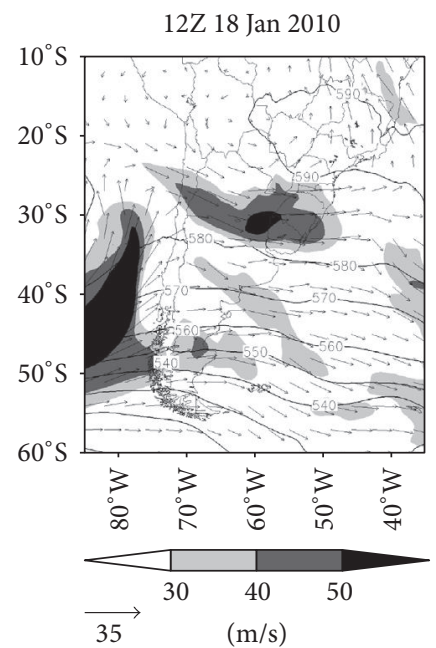

(a)

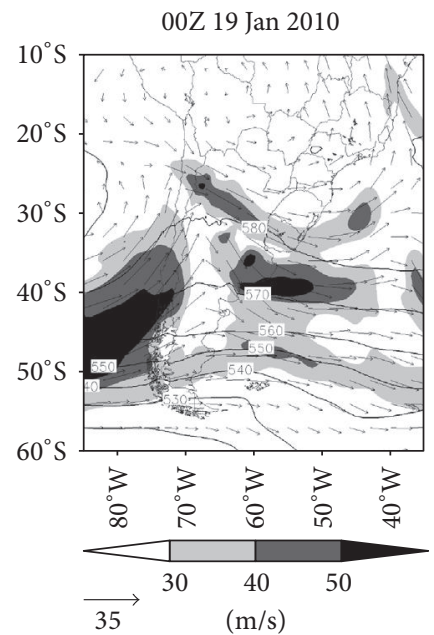

(d)

12Z 19 Jan 2010

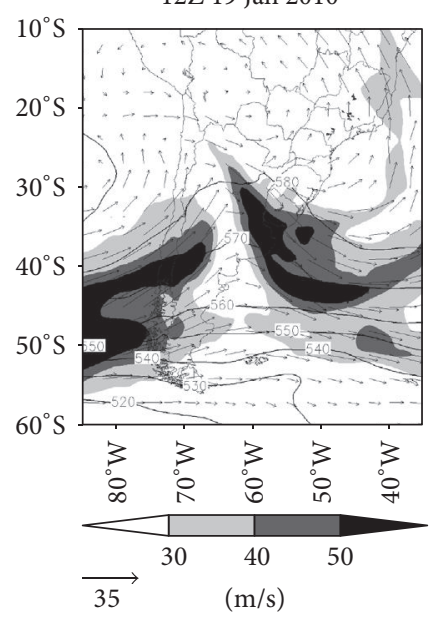

(g)

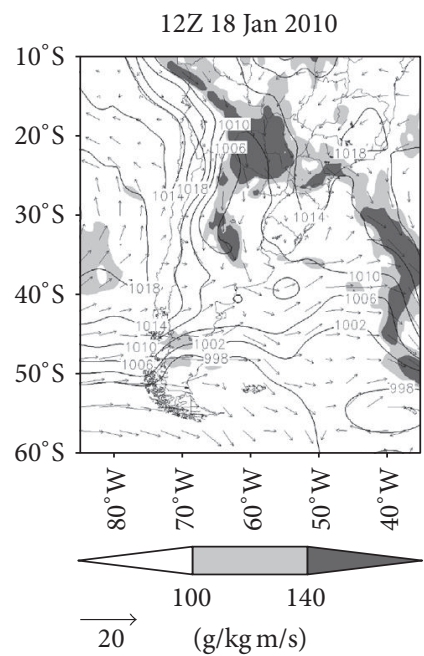

(b)

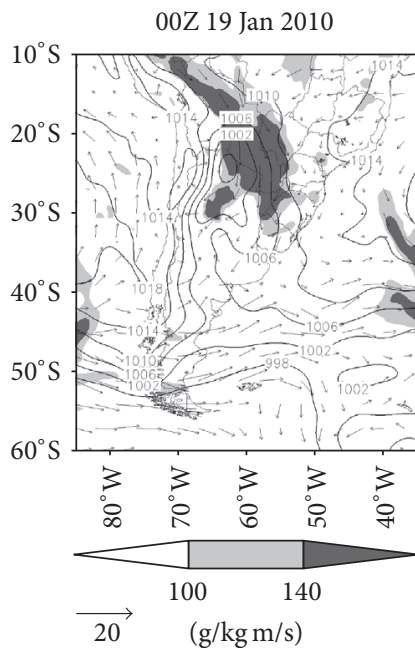

(e)

$12 Z 19$ Jan 2010

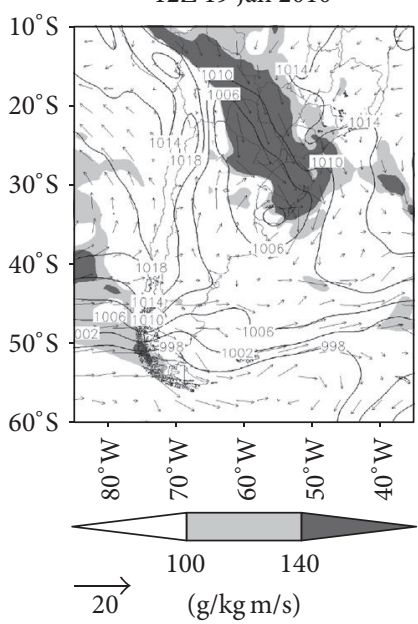

(h)

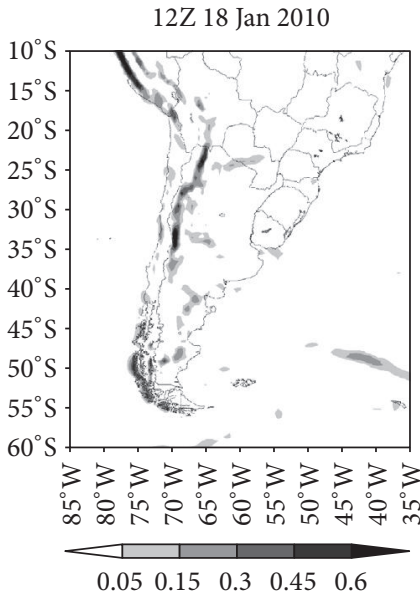

(c)

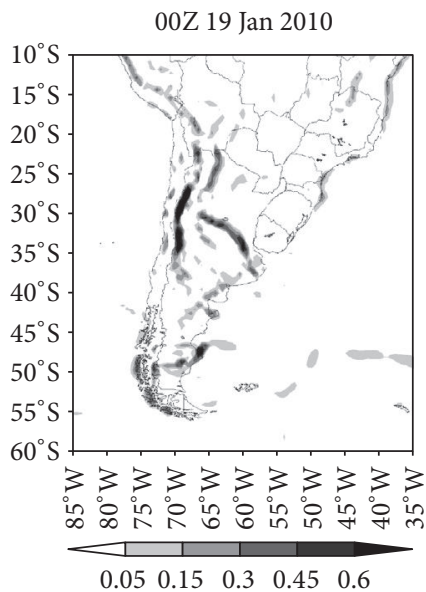

(f)

12Z 19 Jan 2010

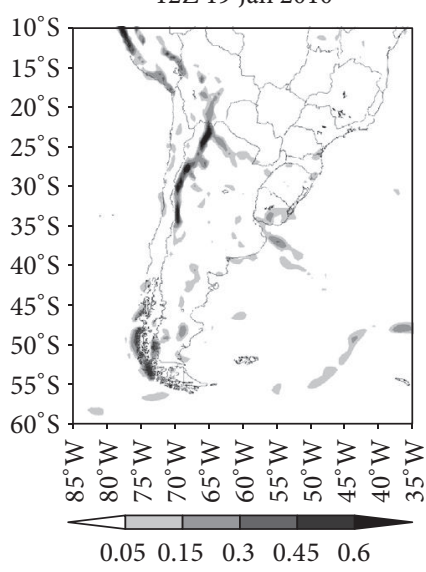

(i)

Figure 5: Same as in Figure 4 but valid at $12 \mathrm{Z} 18$ January 2010 ((a)-(c)), $00 \mathrm{Z} 19$ January 2010 ((d)-(f)), and $12 \mathrm{Z} 19$ January 2010 ((g)-(i)). 


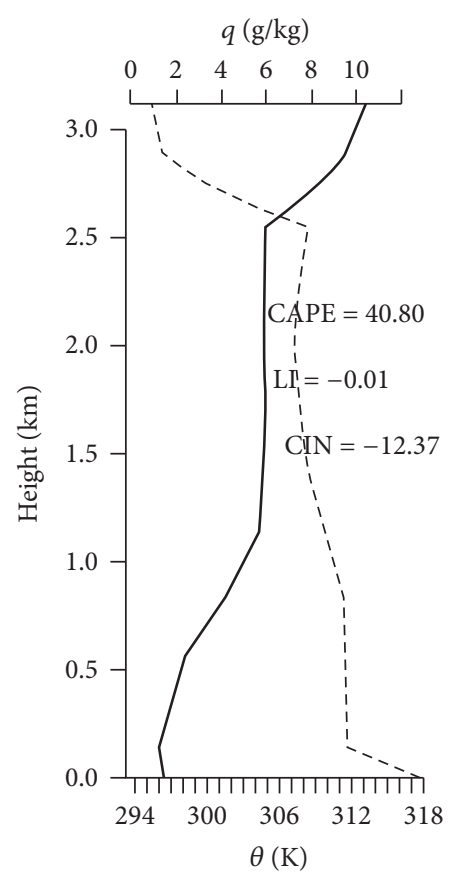

(a)

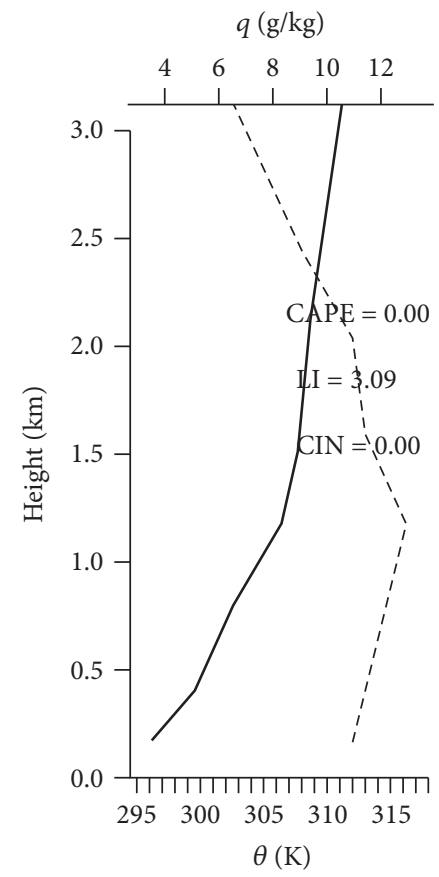

(c)

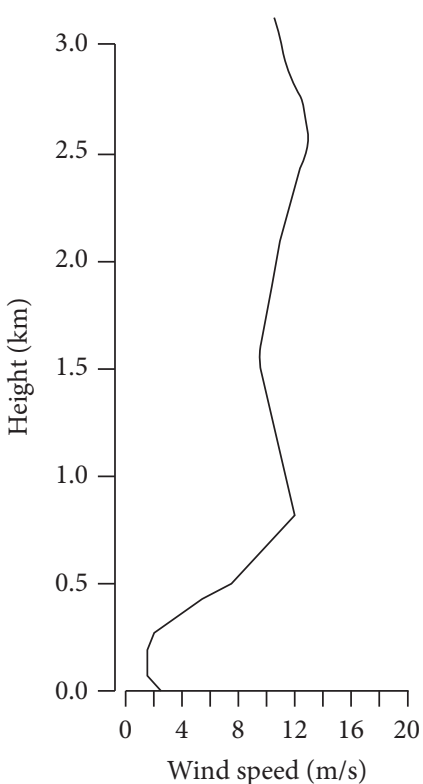

(b)

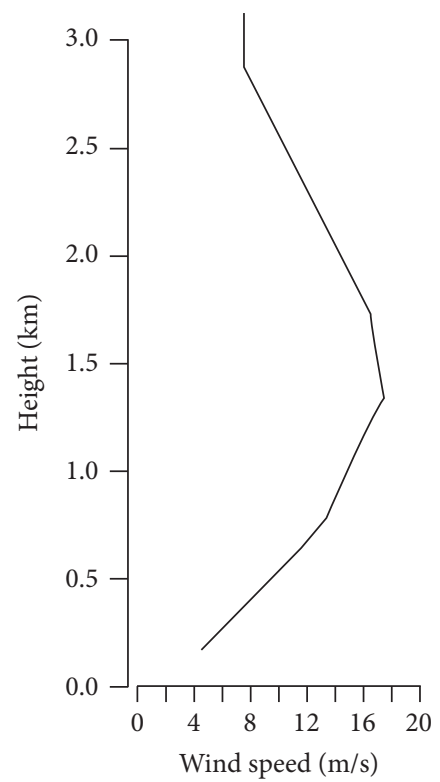

(d)

FIGURE 6: Vertical profiles of potential temperature (thick solid lines, in K), water vapor mixing ratio (dashed lines, in $\mathrm{g} \mathrm{kg}^{-1}$ ), and wind speed (thin solid lines, in $\mathrm{m} \mathrm{s}^{-1}$ ) from surface to $3 \mathrm{~km} \mathrm{AGL} \mathrm{observed} \mathrm{at} 12 \mathrm{Z} 21$ October 2008 for ((a)-(b)) SBPA and ((c)-(d)) SBFI.

the surface, the NAL developed and migrated downstream towards Paraguay creating an inverted trough that extended as far south as the mouth of the La Plata river, with NW-toSE orientation (Figures 5(b), 5(e), and 5(h)). After the MCS's demise, such synoptic evolution led to the early stages of cyclogenesis over the Uruguayan coast (Figure 5(h)). Some baroclinicity was in place at the initiation time of the MCS, as indicated by the frontogenetic function over central-eastern Argentina at $00 \mathrm{Z}$ of 19 January (Figure 5(f)), but the MCS life cycle was observed further north (see Figure 2(b)) of such developing frontal system, at the exit of the $850 \mathrm{hPa}$ moist northerly flow in northeastern Argentina. For this case, the upper level jet stream, at the initiation time of the MCS (Figure 5(d)), was not as strong as the one previously 


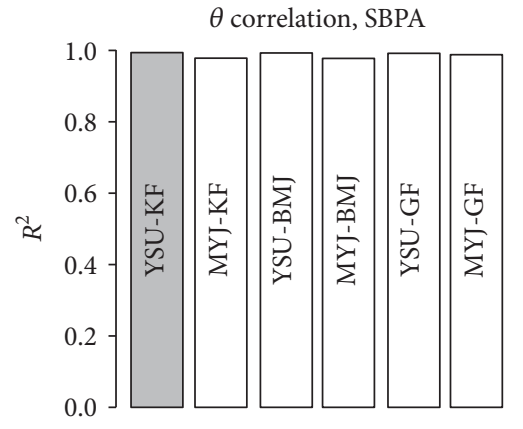

(a)

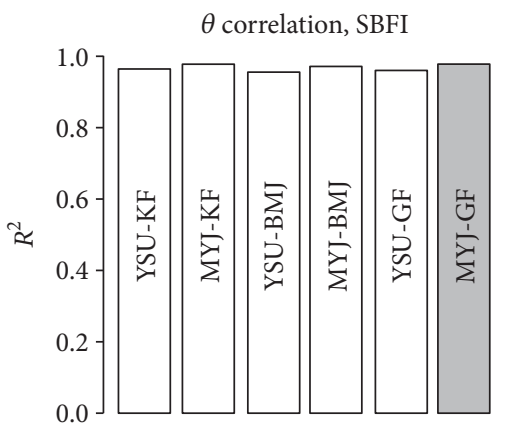

(c)

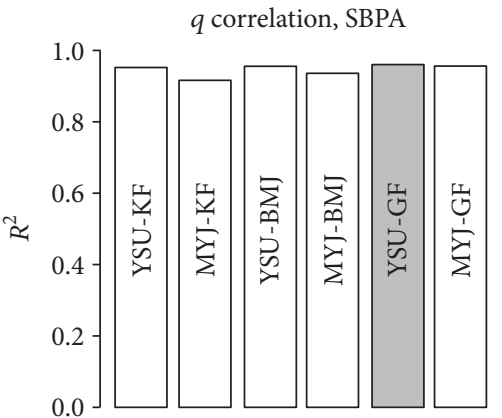

(b)

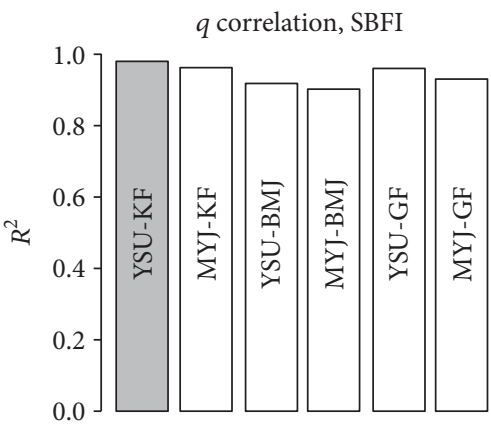

(d)

Figure 7: Pearson correlation coefficients between simulated and observed 0-3 km profiles of potential temperature [(a) and (c)] and water vapor mixing ratio [(b) and (d)] at SBPA [(a)-(b)] and SBFI [(c)-(d)] sites at 12Z 21 October 2008. Shaded bars indicate the simulations with highest correlation coefficients.

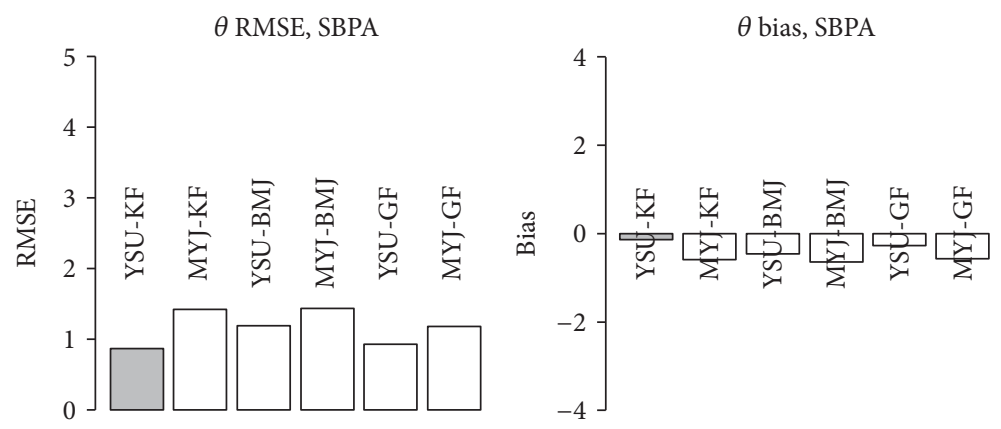

(a)

(b)

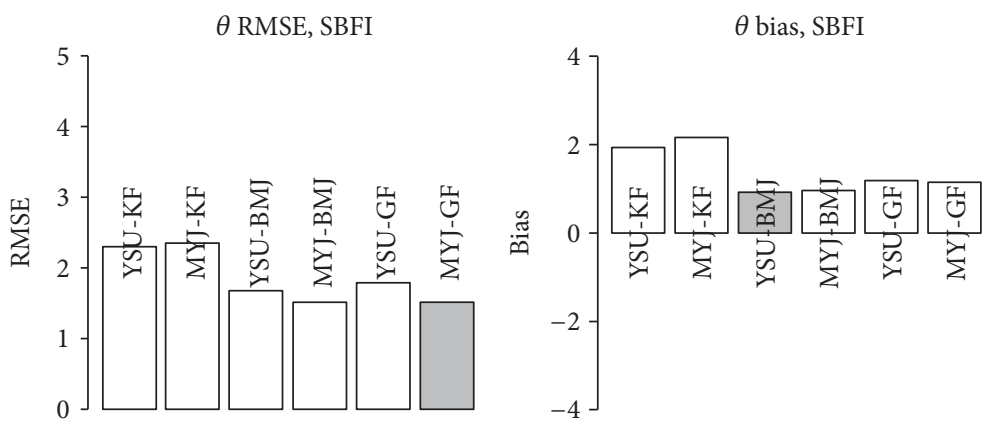

(c)

(d)

FIGURE 8: Root mean square error [(a) and (c)] and bias [(b) and (d)] for the simulated profiles of potential temperature at SBPA [(a)-(b)] and SBFI [(c)-(d)] sites valid at 12Z 21 October 2008. Shaded bars indicate the simulations with lowest RMSE and bias. 


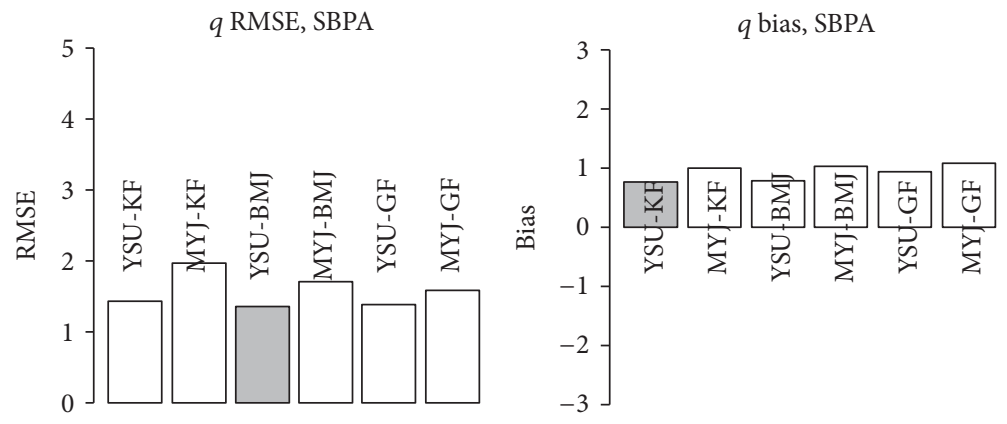

(a)

(b)

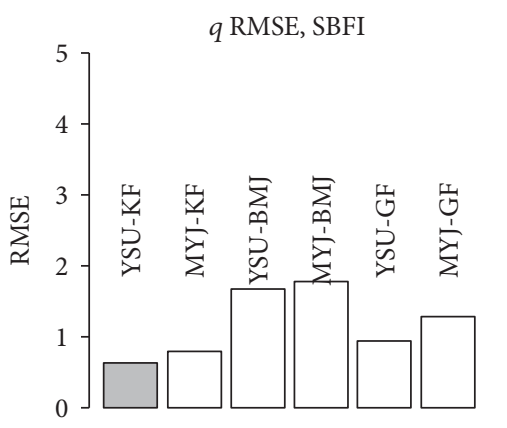

(c)

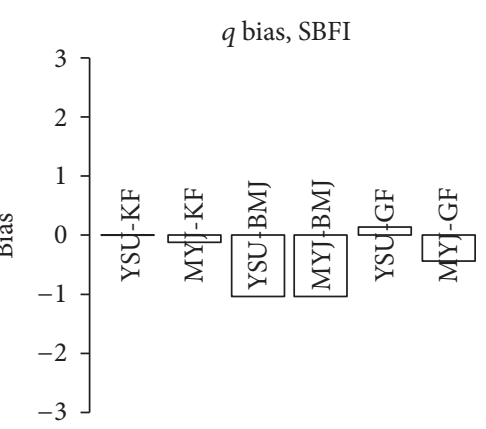

(d)

FIGURE 9: As in Figure 8 but for the simulated profiles of water vapor mixing ratio at SBPA [(a)-(b)] and SBFI [(c)-(d)] sites.

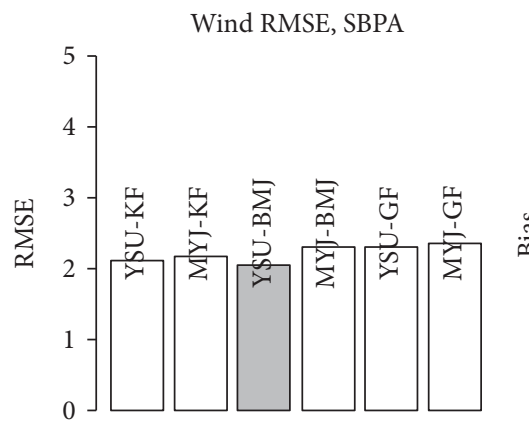

(a)

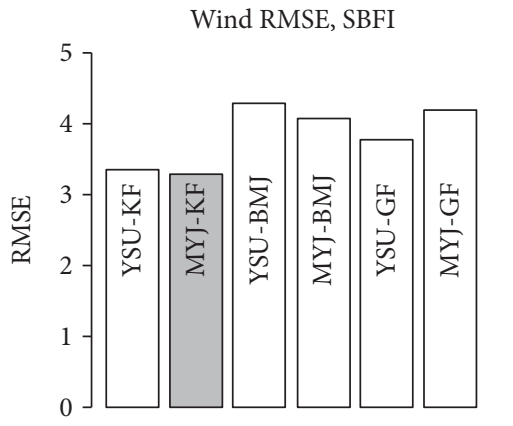

(c)

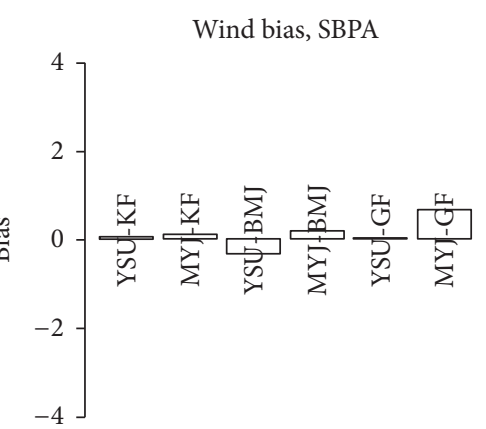

(b)

Wind bias, SBFI

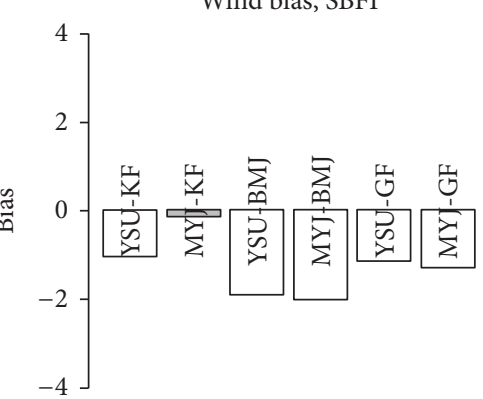

(d)

FIGURE 10: As in Figure 8 but for the simulated wind profiles at SBPA [(a)-(b)] and SBFI [(c)-(d)] sites. 


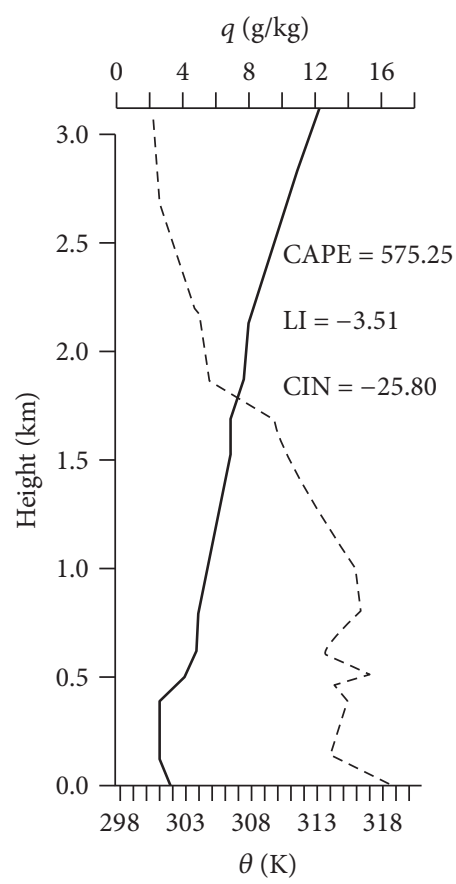

(a)

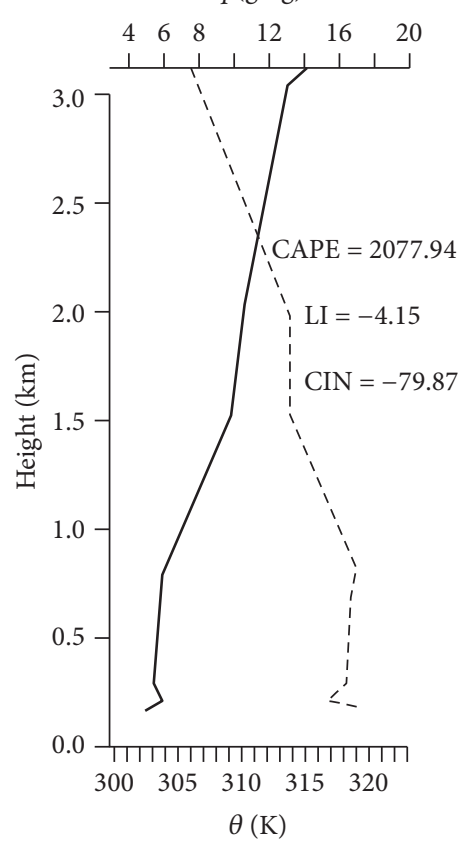

(c)

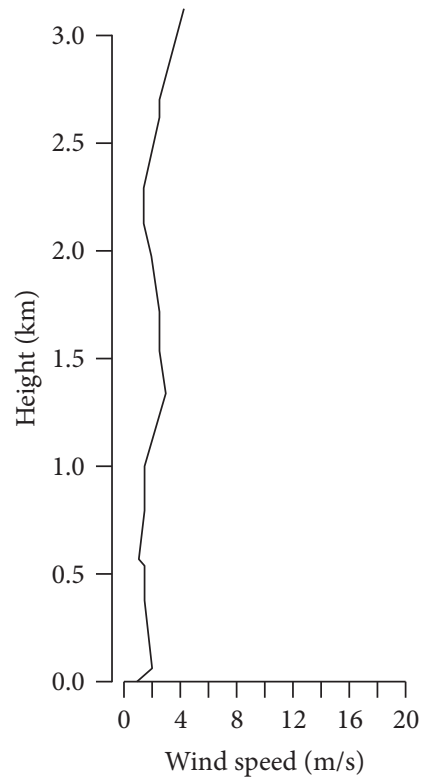

(b)

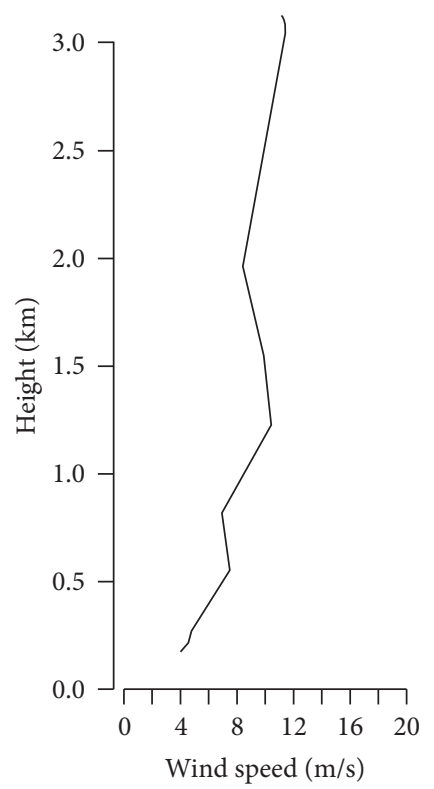

(d)

Figure 11: Same as in Figure 6 but for profiles observed at $12 Z 18$ January 2010 for ((a)-(b)) SBPA and ((c)-(d)) SBFI.

described. This case was selected as a MCS development under a nonfrontal forcing.

\subsection{Analysis of the Lower-Tropospheric Profiles}

3.2.1. Case 1: $12 Z$ of 21 October 2008. The actual lowertropospheric profiles of $\theta$, qv, and winds observed in SBPA, southern Brazil, at $12 \mathrm{Z}$ (9 AM local standard time) of 21 October 2008 are depicted in Figures 6(a) and 6(b).

The temperature profile was isothermal between $500 \mathrm{~m}$ and $1000 \mathrm{~m} \mathrm{AGL}$, while a well-mixed (residual) layer was characterized from $1500 \mathrm{~m}$ to $2500 \mathrm{~m}$ AGL, in which both $\theta$ and qv remained approximately constant (Figure 6(a)). Close to the surface, the qv profile displayed a vertical gradient in 


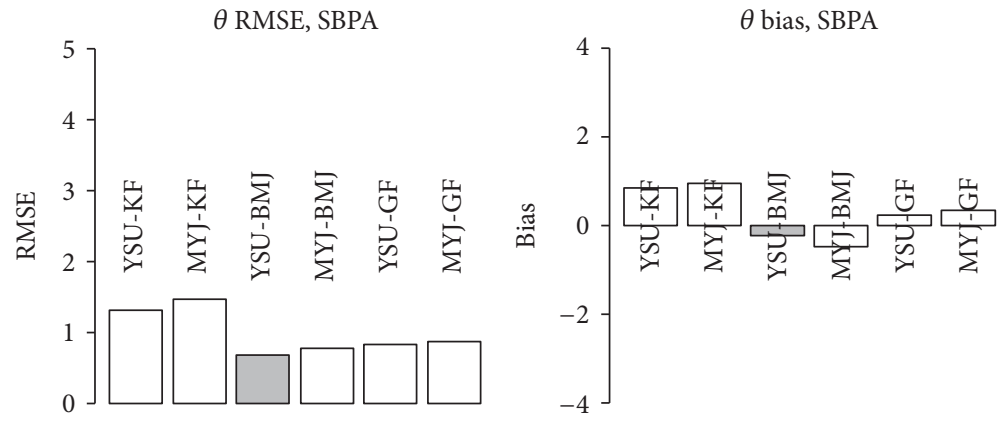

(a)

(b)

$\theta$ RMSE, SBFI

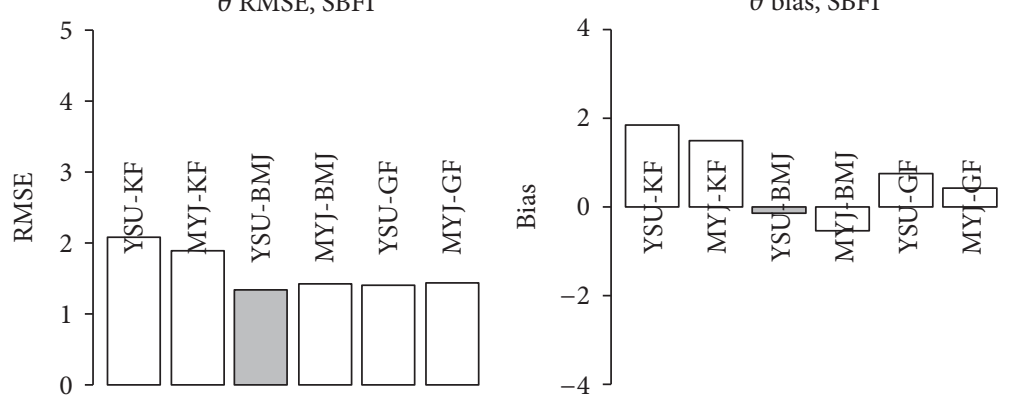

(c)

(d)

FIgURE 12: As in Figure 8 but for the simulations evaluated at $12 \mathrm{Z} 18$ January 2010.

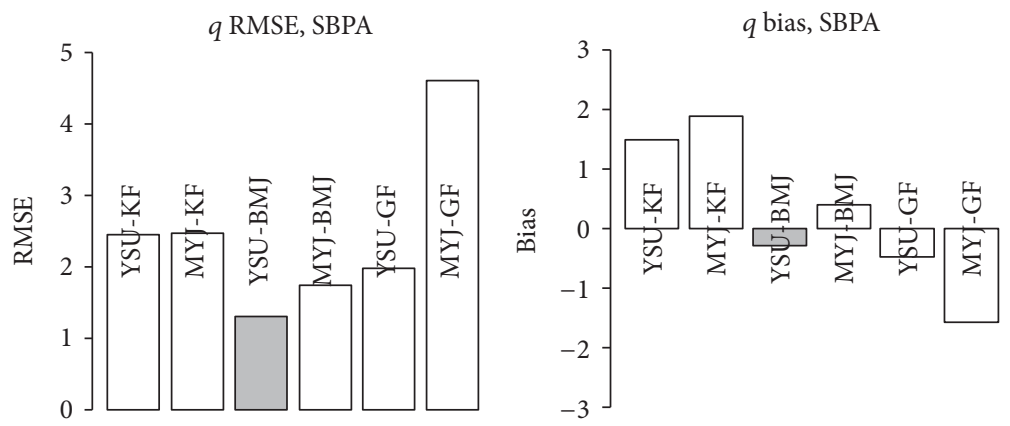

(a)

(b)

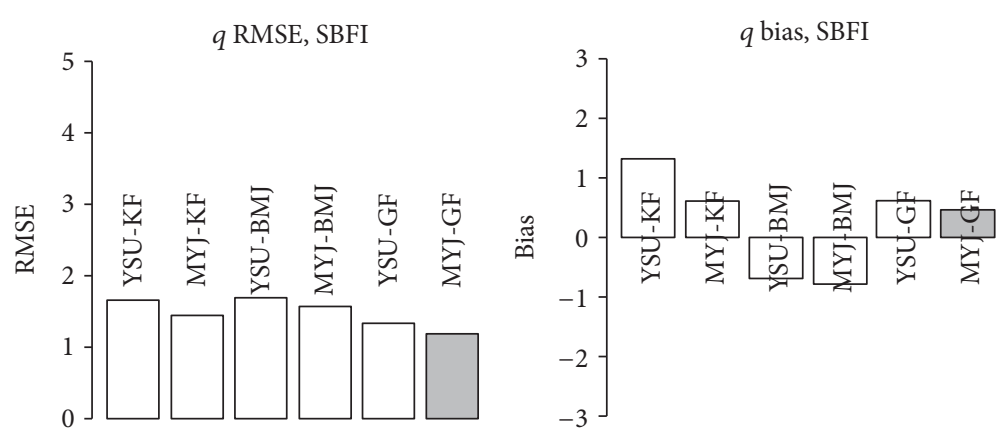

(c)

(d)

FIGURE 13: As in Figure 8 but for the simulated profiles of water vapor mixing ratio at SBPA [(a)-(b)] and SBFI [(c)-(d)] sites evaluated at 12Z 18 January 2010. 


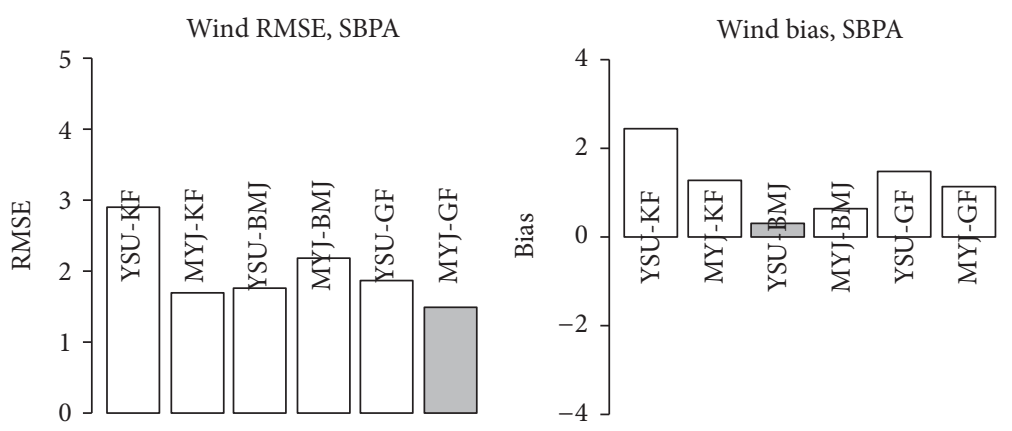

(a)

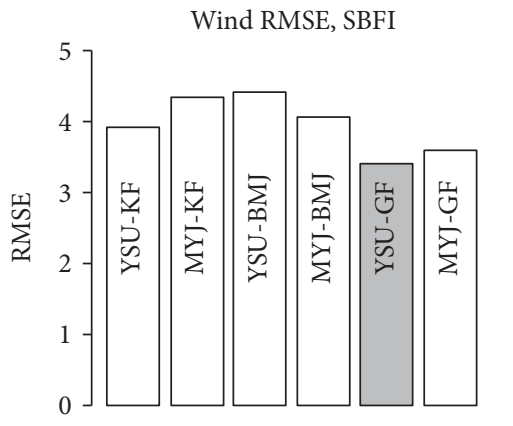

(c) (b)

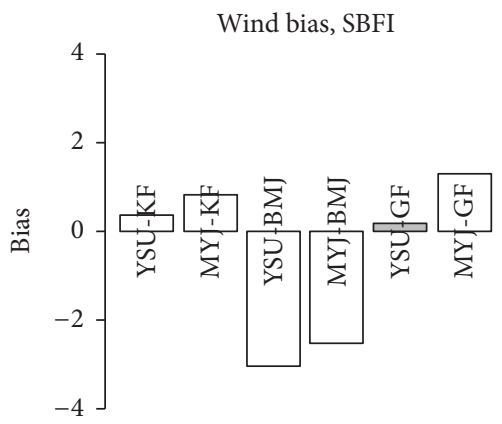

(d)

FIGURE 14: As in Figure 8 but for the simulated wind profiles at SBPA [(a)-(b)] and SBFI [(c)-(d)] sites evaluated at $12 \mathrm{Z} 18$ January 2010.

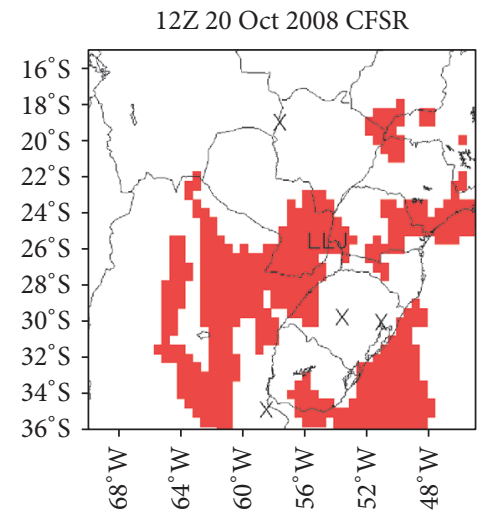

(a)

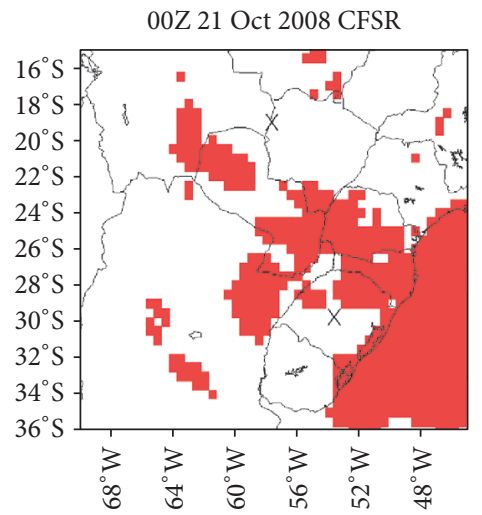

(b)

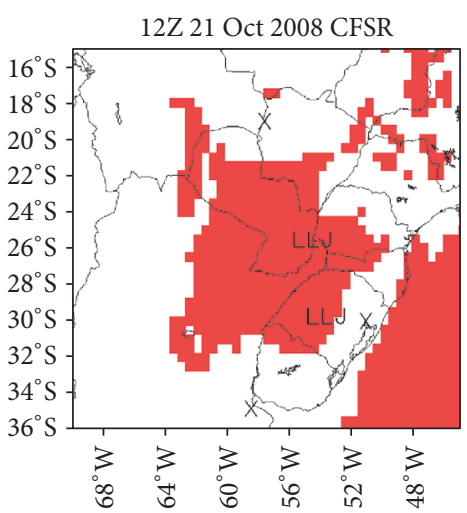

(c)

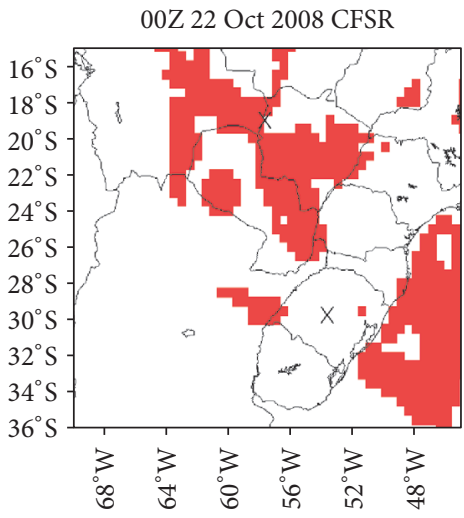

(d)

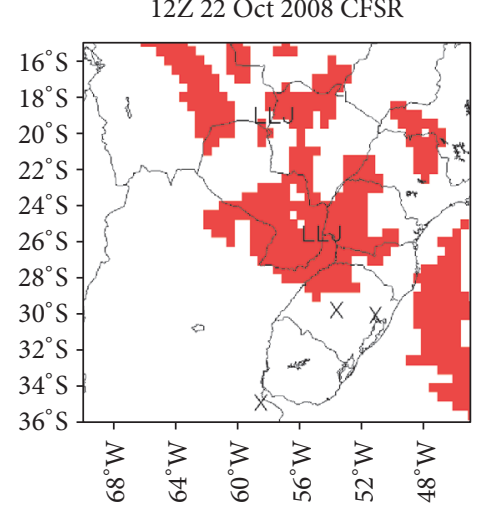

(e)

FIGURE 15: Time evolution of the spatial distribution of grid points from the NCEP-CFS Reanalysis data where a LLJS was identified over the La Plata Basin from (a) 12Z 20 October 2008 to (e) $12 \mathrm{Z} 22$ October $2008 \mathrm{in} 12 \mathrm{hr}$ intervals. Red areas indicate the identification of a LLJS with the NCEP-CFSR data, while the label "LL)" ["X"] indicates an upper air meteorological station, where a LLJS was [was not] characterized. 


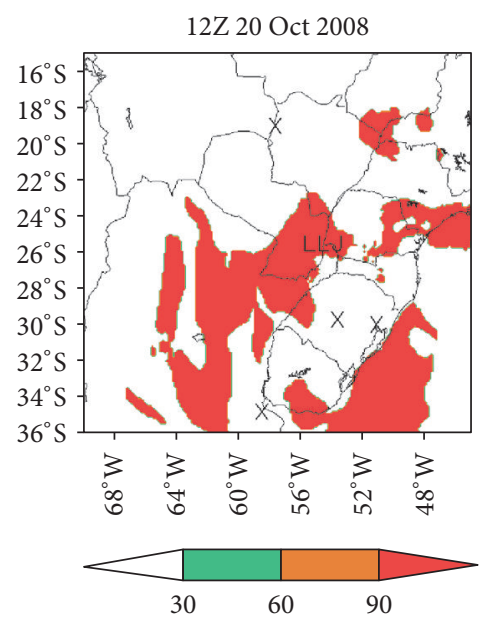

(a)

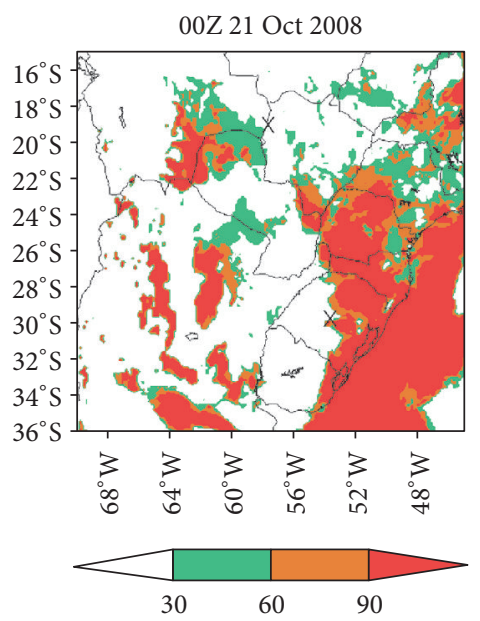

(b)

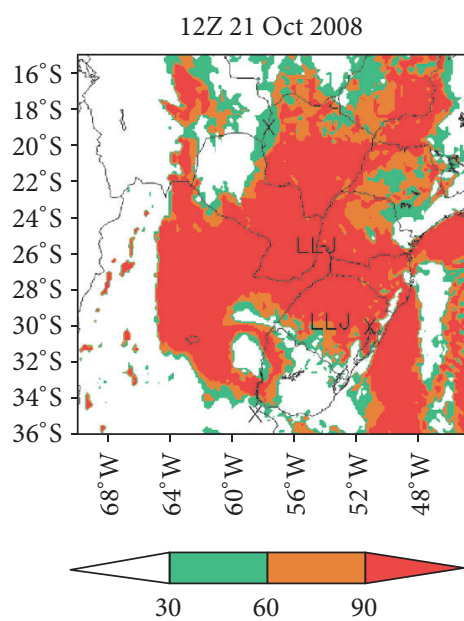

(c)

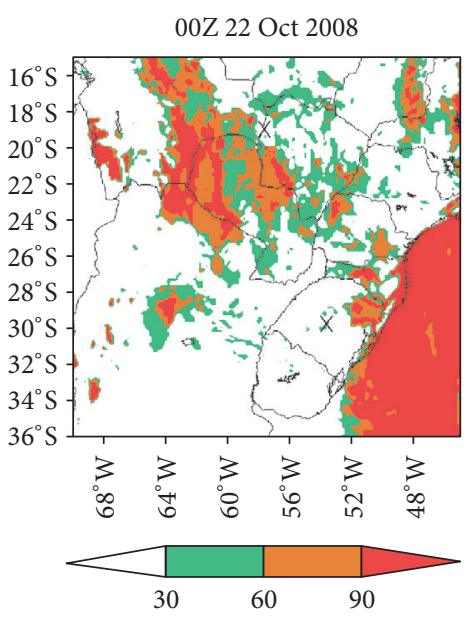

(d)

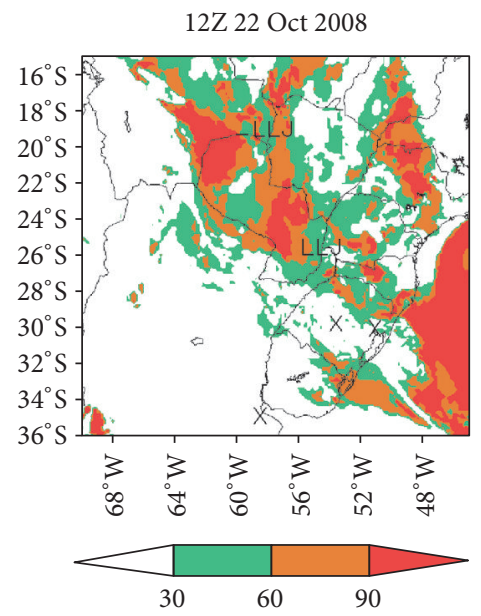

(e)

FIGURE 16: Time evolution of the spatial distribution of grid points from the ARW-WRF simulations where a LLJS was characterized from (a) $12 \mathrm{Z} 20$ October 2008 (model initial condition) to (e) $12 \mathrm{Z} 22$ October $2008 \mathrm{in} 12 \mathrm{hr}$ intervals. The color shading indicates, for the corresponding grid points, the percentage number of simulations employing the MYJ PBL parameterization scheme which generated a LLJS. The shading scale is indicated on the bottom of (a)-(e). The label "LLJ" ["X"] indicates an upper air meteorological station, where a LLJS was [was not] characterized.

a shallow layer before becoming well mixed within a $500 \mathrm{~m}$ deep layer aloft. Above $2500 \mathrm{~m}$, a decrease in qv and increase in $\theta$ were observed with height. The wind profile (Figure 6(b)) displayed vertical shear in the lowest $1000 \mathrm{~m}$ with a local maximum in magnitude reaching $12 \mathrm{~m} / \mathrm{s}$ around $800 \mathrm{~m}$. Above this local maximum and up to $3000 \mathrm{~m}$, the wind speeds did not vary considerably, and the LLJS criteria were not met for this upper air station at this time. The corresponding profiles at SBFI (Figures 6(c) and 6(d)), approximately $600 \mathrm{~km}$ to the northwest of SBPA, displayed a distinct lower-tropospheric environment compared to the one observed in SBPA, except for the presence of an isothermal layer from $500 \mathrm{~m}$ to $1200 \mathrm{~m}$ AGL, which was roughly a similar finding. In this profile, there was no well-defined mixed layer (Figure 6(c)). The vertical wind shear was also stronger in SBFI (Figure 6(d)), displaying a well-outlined maximum in the wind magnitude just below $1500 \mathrm{~m}$ AGL, reaching $18 \mathrm{~m} / \mathrm{s}$. The LLJS criteria were met for this upper air station at this time.
Figure 7 shows the correlation coefficient between the predicted and actual profiles of $\theta$ and qv in SBPA and SBFI in the lowest $3 \mathrm{~km}$ for all six simulations. Overall, the correlation coefficients for both variables were high, with only minor distinctions among the experiments. However, when RMSE and bias are analyzed (Figure 8), some differences become distinguishable.

First, all simulations verified at SBPA displayed better skill scores (i.e., lower RMSE and bias) for $\theta$ than at SBFI (Figure 8), while for qv (Figure 9) skill scores did not show clear discrimination among the simulations and the two sites. Interestingly, at SBPA, the simulations showed a slightly cold and moist bias (Figures 8(b) and 9(b)), whereas at SBFI a warm and (mostly) dry bias was found (Figures $8(\mathrm{~d})$ and $9(\mathrm{~d})$ ). The observed profile (Figure 6) was only slightly warmer but considerably moister in SBFI than in SBPA.

$\mathrm{Hu}$ et al. [9] reported a cold bias in simulated profiles using WRF with local or nonlocal PBL schemes, with the local 


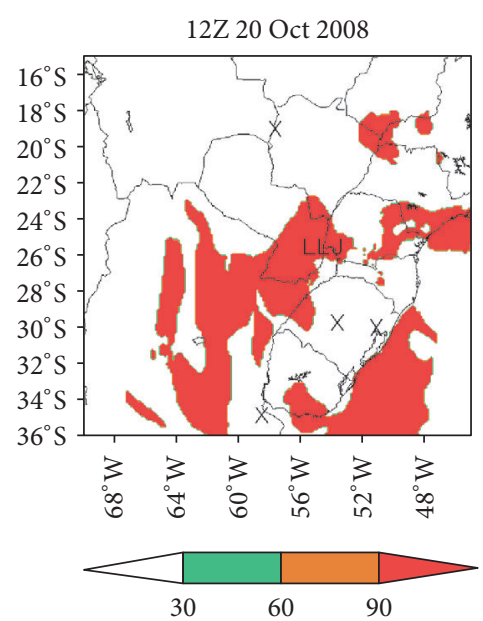

(a)

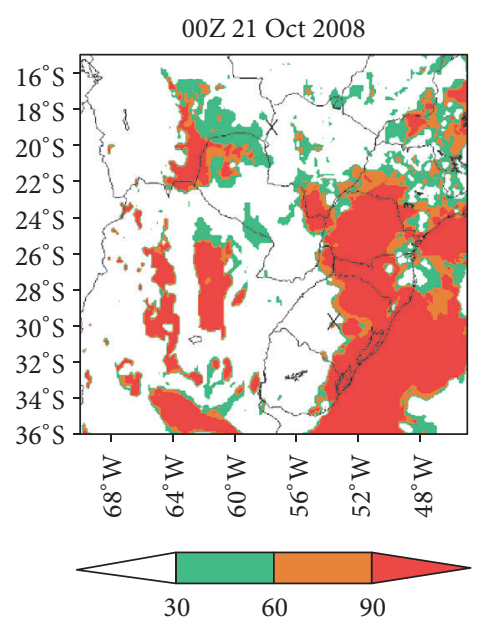

(b)

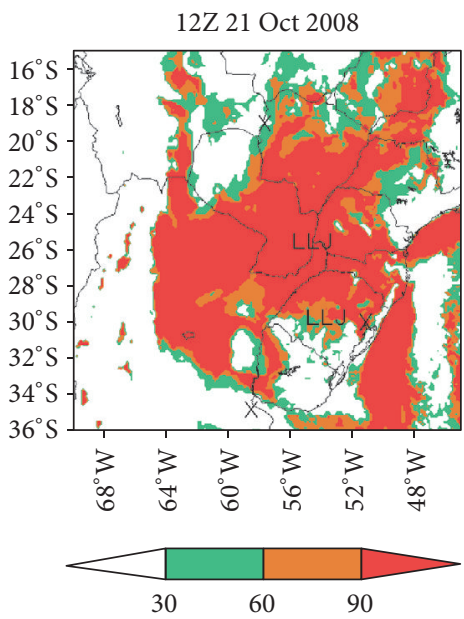

(c)

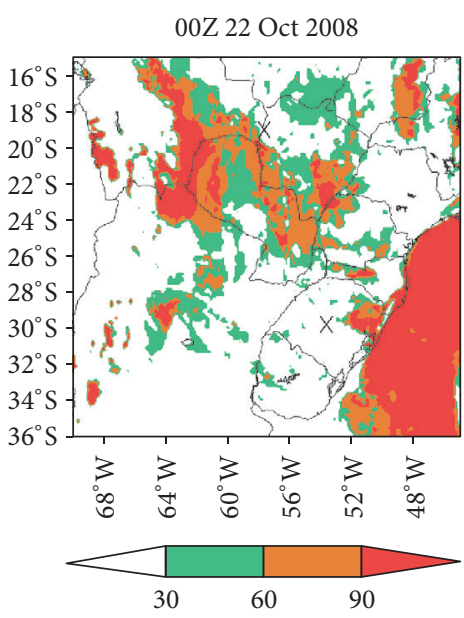

(d)

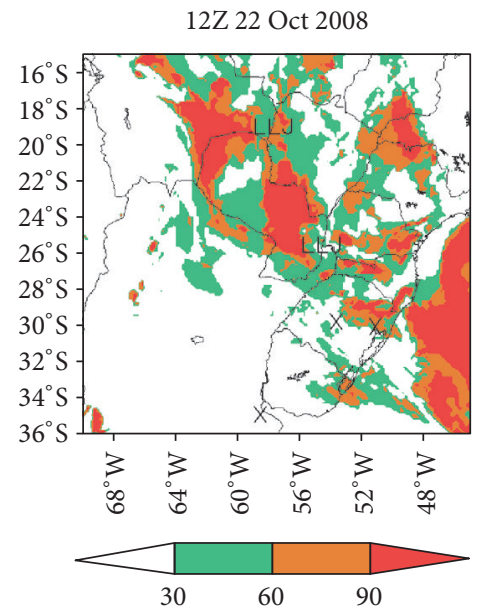

(e)

FIGURE 17: As in Figure 16 but for the simulations employing the YSU PBL parameterization scheme.

scheme (MYJ) showing slight tendency towards a colder bias. In agreement, at SBPA, the simulations with MYJ scheme were the ones with the most negative bias in $\theta$ (Figure 8(b)); however, at SBFI, not only was the bias positive, but also nearly no distinction was found among the simulations with MYJ and YSU schemes (Figure 8(d)). In terms of RMSE, most of the runs employing the YSU scheme displayed slightly better scores for both $\theta$ and qv at both sites, with notable exceptions being for the YSU-BMJ and YSU-GF simulations for $\theta$ at SBFI (Figure 8(c)).

As for the wind profile (Figure 10), simulations verified at SBPA showed considerably higher skill scores than those at SBFI. In fact, bias close to zero was found at SBPA (Figure 10(b)), while, at SBFI, negative bias was found in all simulations (Figure $10(\mathrm{~d})$ ). It is important to recall that at SBFI a LLJS was characterized at this time. Albeit the negative bias in the wind magnitude, most simulated wind profiles at SBFI still met the LLJS criteria. In contrast, while the observed SBPA wind profile did not characterize a LLJS, a LLJS was indicated by most simulated profiles verified at SBPA, which means that the skill scores alone do not provide complete verification of the simulations. One possible reason why the skill scores were worse for SBFI than for SBPA is that the observed hodograph was much noisier at SBFI (not shown).

3.2.2. Case 2: $12 Z$ of 18 January 2010. Figure 11 illustrates the lower-tropospheric profiles of $\theta$, qv, and winds at SBPA and SBFI at $12 Z$ of 18 January 2010 . The SBPA $\theta$ profile depicted a shallow neutral layer below $500 \mathrm{~m}$ AGL, followed by a stable stratification aloft (Figure 11(a)), while the corresponding qv profile showed a moderately intense moisture gradient from $1000 \mathrm{~m}$ to $2000 \mathrm{~m} \mathrm{AGL}$, with the upper one-third of the analyzed layer becoming considerably drier than the lowest one-third. The wind profile at SBPA (Figure 11(b)) displayed weak winds and almost no vertical wind shear such that a LLJS was not identified for this site. For SBFI, a shallow mixed layer approximately $800 \mathrm{~m}$ in depth was observed (Figure 11(c)) with stable stratification and drier layer above. Both SBPA and SBFI profiles were considerably moister than the 20 October 2008 counterparts. Regarding the wind profile at SBFI (Figure 11(d)), the winds were stronger than winds at SBPA and some vertical wind shear was present; however, no LLJS was characterized. 


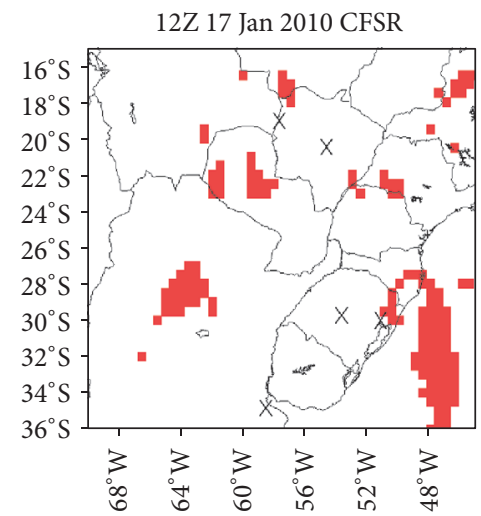

(a)

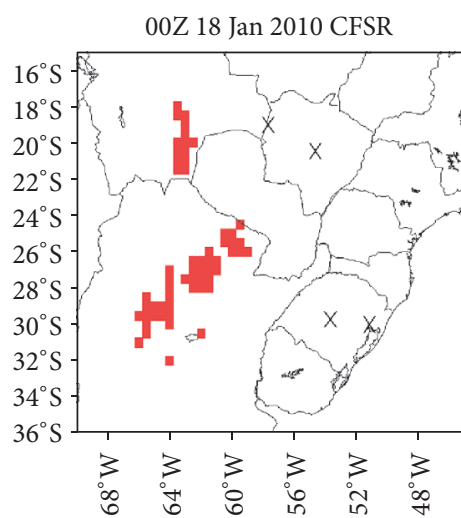

(b)

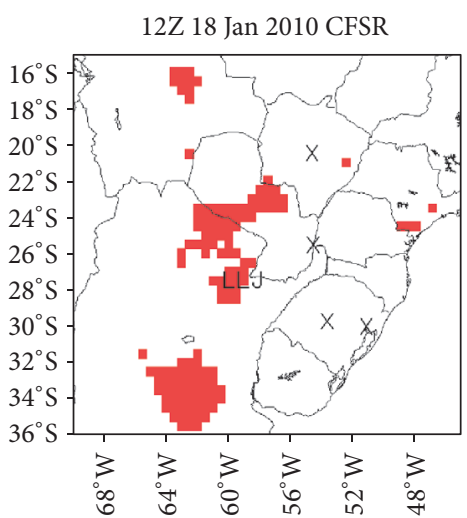

(c)

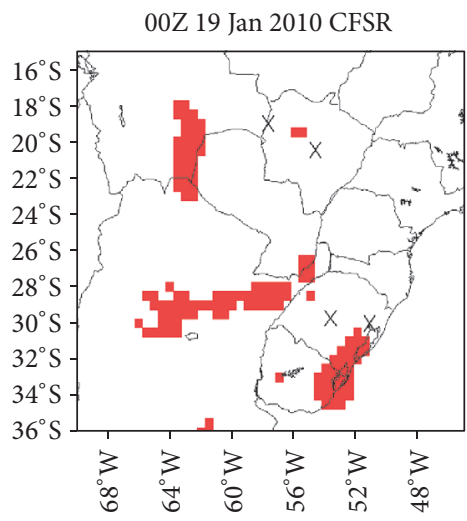

(d)

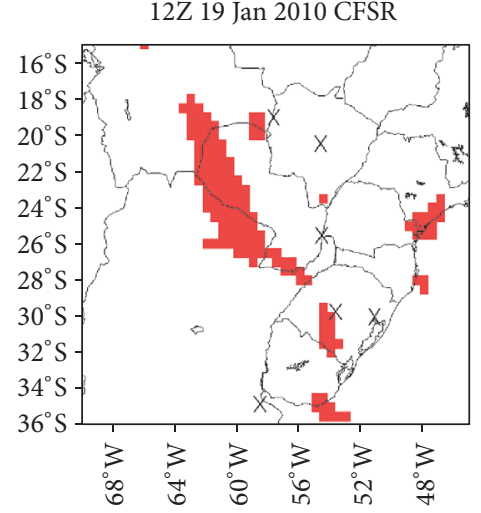

(e)

FIgURE 18: As in Figure 15 but from (a) $12 \mathrm{Z} 17$ January 2010 to (e) $12 \mathrm{Z} 19$ January 2010.

The correlation coefficients for the $0-3 \mathrm{~km}$ profiles of $\theta$ and qv in SBPA and SBFI for all simulations were high (above 0.9; not shown), except for qv at SBPA for the simulation using MYJ and GF schemes, for which the correlation was around 0.5. Similar to Case 1, the RMSE and bias for the simulations verified at SBPA displayed, in general, lower RMSE and bias compared to SBFI for $\theta$ profile (Figure 12). One interesting distinction with respect to Case 1 is that the bias in $\theta$ among the simulations verified at SBPA shows a very similar behavior to the one found for SBFI (Figures 12 (b) and 12(d)), with a slightly warm bias for all simulations except for the ones employing the YSU and BMJ combination. Therefore, despite the general warm bias found at SBFI site in the two cases, it is not possible to generalize on the sign of the bias for all locations. The low correlation coefficient obtained for the simulated qv profile at SBPA for the experiment utilizing the MYJ-GF combination is in agreement with the highest RMSE and driest bias found for this very simulation among all combinations of parameterization schemes and among the two sites (Figure 13). The behavior of most solutions at SBFI changed from a dry bias in Case 1 to a predominantly moist bias in Case 2 (Figure 13(d)).

Regarding the wind profile (Figure 14), experiments verified at SBPA again displayed lower RMSE than that at SBFI, but with a stronger positive bias than the one found for Case 1. In Case 2, the observed winds at SBPA were much weaker
(Figure 14(b)) than in Case 1, and most simulations failed to reproduce such a low speed profile. At SBFI, negative bias was found only for the two experiments employing the BMJ convective scheme, with the remaining simulations showing slight tendency towards a positive bias (Figure 14(d)), which differs from the result found for Case 1.

Overall, the verification indicates a relevant case-to-case variability in the skill of the simulations in reproducing the observed thermodynamic and kinematic profiles, but in general it was found that the simulations utilizing the YSU PBL scheme produced better results.

\subsection{Areal Coverage of the Simulated LLJS}

3.3.1. Case 1: From 20 to 22 October 2008. The panels in Figure 15 depict the time evolution, in 12-hour intervals starting at $12 \mathrm{Z}$ of 20 October 2008, of the spatial distribution of LLJS over the La Plata Basin based on CFSR data and on upper air observations at (up to) five sounding sites in Brazil and Argentina. Despite few observations available to verify the CFSR data, it appears that CFSR succeeded in flagging correctly locals where the LLJS was in place and also locals where it was not characterized. Thus, we use the CFSR data to perform general verification of the WRF simulations.

Figures 16 and 17 illustrate the corresponding maps of the time evolution of the LLJS spatial distribution for 


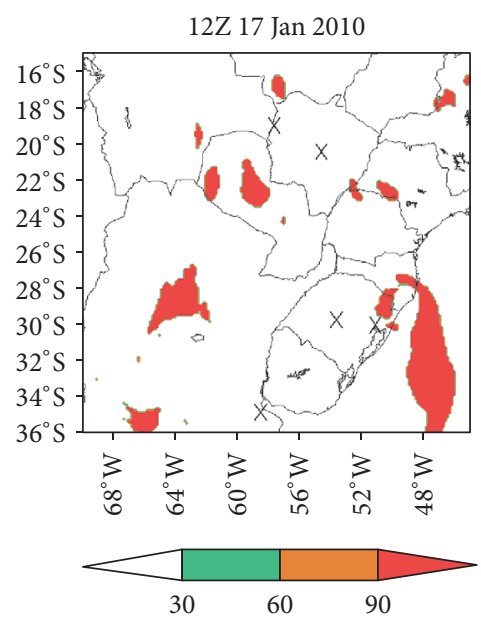

(a)

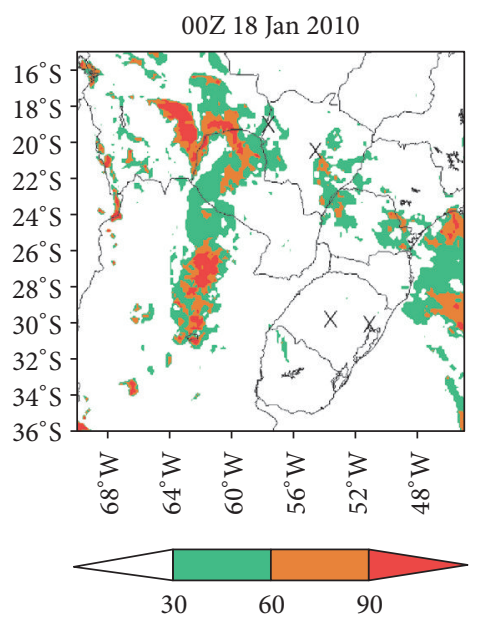

(b)

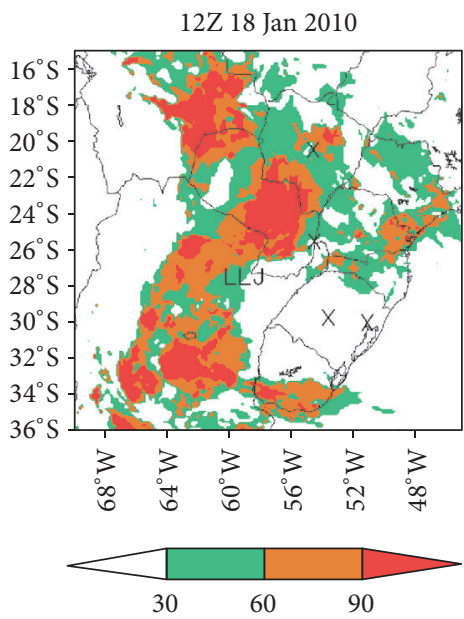

(c)
00Z 19 Jan 2010

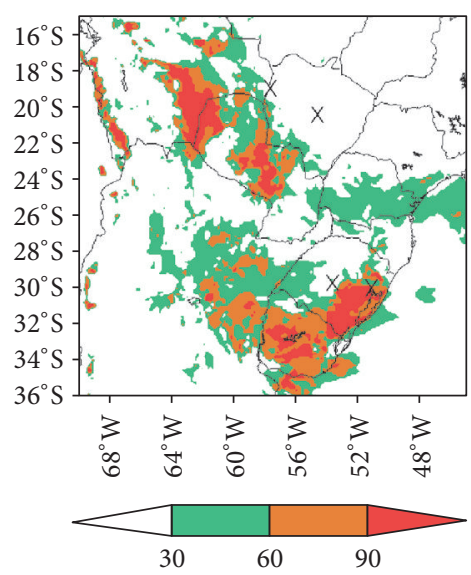

(d)

$12 Z 19$ Jan 2010

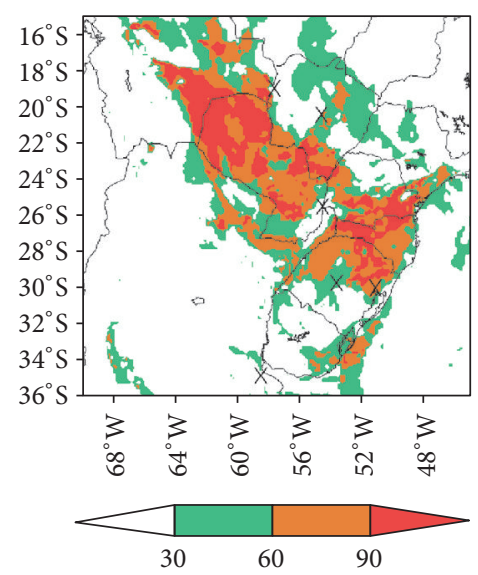

(e)

Figure 19: As in Figure 16 but from (a) 12Z 17 January 2010 (model initial condition) to (e) 12Z 19 January 2010.

WRF simulations utilizing the 12 distinct combinations of $\mathrm{PBL}$ and convective parameterization schemes. The shading in Figure 16 (Figure 17) shows the percentage number of simulations using MYJ (YSU) scheme for which the LLJS was characterized to be compared with the respective panels in Figure 15 for the CFSR data. In general, simulations with MYJ and YSU generated similar spatial patterns and percentage numbers among them. The $90 \%$ shading dominated the spatial distribution in the first $24 \mathrm{hr}$ of simulation, and, as expected, areas with lower percentages became more widespread at the end of the simulations, indicating increased dispersion of the numerical solutions as the time integration proceeded. It is interesting to note that at the 48th hour of integration (Figures 16(e) and 17(e)) a lower number of simulations reproduced a LLJS around the sounding sites, where a LLJS was effectively observed at the Brazil-Paraguay and Brazil-Bolivia borders. When compared to the CFSR data, simulations with MYJ and YSU schemes for this case displayed tendency to overestimate the areas with LLJS. Among the experiments using MYJ and YSU schemes, the ones utilizing the local scheme produced a slightly higher number of grid points, where a LLJS was characterized, suggesting weaker vertical momentum mixing by the MYJ scheme at night (note that the simulations were verified at 9 $\mathrm{AM}$ and 9 PM local standard time over the La Plata Basin), a finding that was also reported in other studies $[9,22]$.

3.3.2. Case 2: From 17 to 19 January 2010. Figure 18 displays the time evolution, in 12-hour intervals starting at $12 \mathrm{Z}$ of 17 January 2010, of the spatial extent of CFSR grid points, where LLJS criteria were satisfied, as well as the LLJS detection by actual soundings. Note that, for this weak frontal forcing situation, LLJS profiles were flagged in fewer regions by both observations and CFSR data. In fact, only at Resistencia, in extreme northern Argentina, at $12 \mathrm{Z}$ of 18 January (Figure 18(c)), did the observed wind profile met LLJS conditions. The corresponding profile extracted from CFSR also characterized a LLJS. In agreement with this general finding, all WRF simulations reproduced smaller areas with LLJS profiles (Figures 19 and 20) compared to the previous case. Also, as a result from the weaker synoptic forcing, the dispersion among the solutions grew much faster than in 


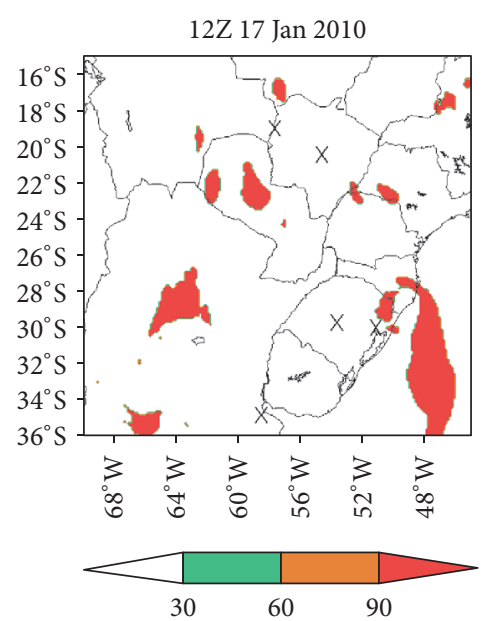

(a)

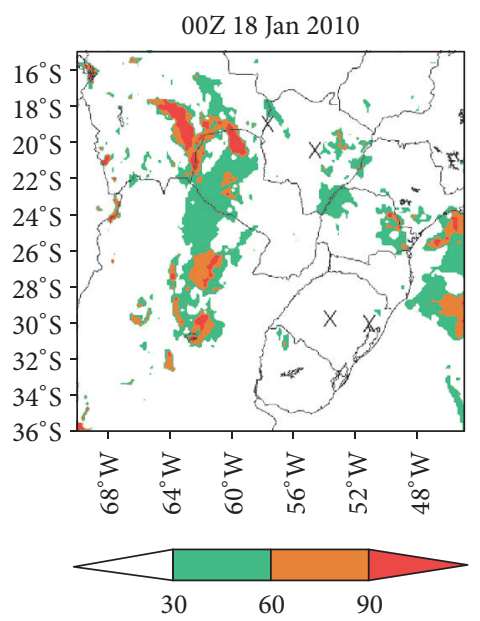

(b)

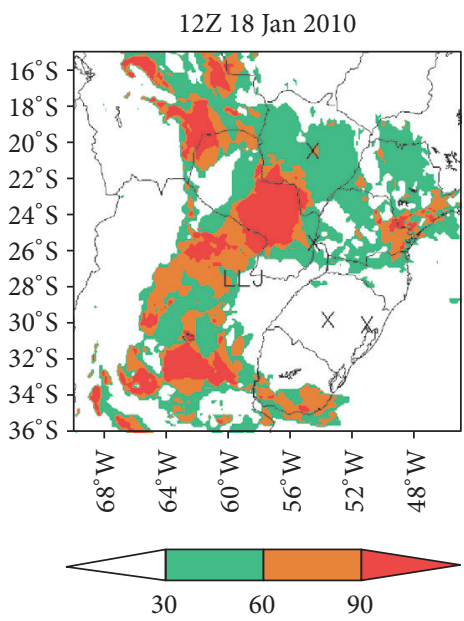

(c)

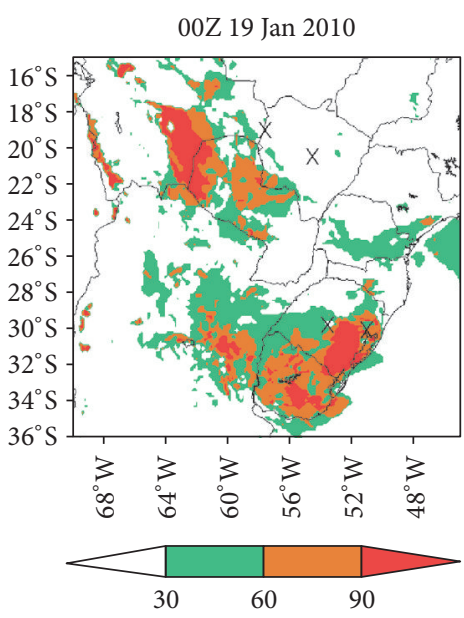

(d)

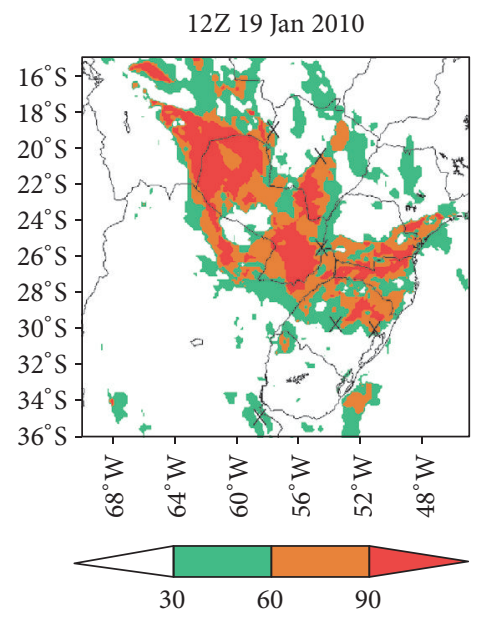

(e)

FIgURE 20: As in Figure 16 but for the simulations employing the YSU PBL parameterization scheme and from (a) $12 Z 17$ January 2010 (model initial condition) to (e) $12 \mathrm{Z} 19$ January 2010.

Case 1 as seen by the larger areas with lower percentage numbers of simulations agreeing in the LLJS criteria after $24 \mathrm{hr}$ of integration (Figures 19(c) and 20(c)).

The overestimation of the area with predicted LLJS profiles when compared to the corresponding CFSR data also stands out in Figures 19 and 20, this being true for experiments employing either YSU or MYJ PBL scheme. This result is in agreement with the (general) positive bias found for wind magnitude when the simulations were locally verified for SBPA and SBFI sites. Comparing the sets of experiments utilizing MYJ and YSU schemes, once again simulations with the MYJ (local) scheme displayed a larger number of grid points, where LLJS were identified. Hence, an overall result from this analysis is that the YSU nonlocal PBL scheme yielded slightly better results.

\section{Conclusions}

This study evaluated the sensitivity of the numerical simulation of the SALLJS to the choice of parameterization schemes for the PBL and for cumulus convection for two cases in which the development of MCSs in the La Plata Basin was observed.

The main finding is that it was not possible to point out the best paired combination of PBL and convective parameterization schemes for the two analyzed cases because of the significant variability of skill scores and of the spatial distribution of profiles predicted with LLJS conditions among the twelve simulations. In addition, there was general tendency for the simulations to overestimate the LLJS occurrence, especially for the experiments utilizing the Mellor-Yamada-Janjić PBL scheme. This last finding agrees with previous studies that also reported that the Mellor-Yamada-Janjić scheme usually leads to positive bias in wind speed because of less vertical momentum mixing during night-time conditions (e.g., [9]).

Our results also confirm that in situations under stronger synoptic forcing it takes longer for the dispersion among simulations using distinct physical schemes to take place. Under weaker synoptic forcing, local processes tend to influence the atmospheric circulation and stability which helps to explain 
the stronger dispersion found for the mid-summer case when the frontal forcing was located further away from the LLJS and MCS activity. It was not possible to reach a conclusion regarding which convective parameterization scheme yielded the best results.

However, among the PBL parameterization schemes, the Yonsei University nonlocal scheme, in general, displayed slightly better results not only in terms of the LLJS identification (for all cases) but also with respect to the representation of the potential temperature profile in the strong synoptic forcing situation. As for the simulation of moisture profiles, highly mixed results among the simulations were found, which prevented an overall conclusion about the best PBL scheme for representing this scalar.

Some of the disagreement between the simulated and observed profiles may have been also influenced by other aspects, such as mismatches in the numerical representation of soil moisture and soil type and vegetation cover (e.g., [11]), not evaluated in this study.

\section{Competing Interests}

The authors declare that there are no competing interests regarding the publication of this paper.

\section{Acknowledgments}

This study was developed as part of the first author's doctoral research at the Graduate Program in Meteorology of the Universidade Federal de Santa Maria in Brazil. The authors wish to thank Dr. Ronald Buss de Souza from the Southern Center of Brazil's National Institute for Space Research, located in Santa Maria, for making available the computing facility necessary to perform the WRF simulations analyzed in this study.

\section{References}

[1] C. Vera, J. Baez, M. Douglas et al., "The South American lowlevel jet experiment," Bulletin of the American Meteorological Society, vol. 87, no. 1, pp. 63-77, 2006.

[2] C. Saulo, J. Ruiz, and Y. G. Skabar, "Synergism between the lowlevel jet and organized convection at its exit region," Monthly Weather Review, vol. 135, no. 4, pp. 1310-1326, 2007.

[3] P. Salio, M. Nicolini, and E. J. Zipser, "Mesoscale convective systems over southeastern South America and their relationship with the South American low-level jet," Monthly Weather Review, vol. 135, no. 4, pp. 1290-1309, 2007.

[4] J. A. Marengo, W. R. Soares, C. Saulo, and M. Nicolini, "Climatology of the low-level jet east of the Andes as derived from the NCEP-NCAR reanalyses: characteristics and temporal variability," Journal of Climate, vol. 17, no. 12, pp. 2261-2280, 2004.

[5] J. D. Tuttle and C. A. Davis, "Corridors of warm season precipitation in the central United States," Monthly Weather Review, vol. 134, no. 9, pp. 2297-2317, 2006.

[6] X. Jiang, N.-C. Lau, I. M. Held, and J. J. Ploshay, "Mechanisms of the great plains low-level jet as simulated in an AGCM," Journal of the Atmospheric Sciences, vol. 64, no. 2, pp. 532-547, 2007.
[7] B. J. Vanderwende, J. K. Lundquist, M. E. Rhodes, E. S. Takle, and S. L. Irvin, "Observing and simulating the summertime low-level jet in central Iowa," Monthly Weather Review, vol. 143, no. 6, pp. 2319-2336, 2015.

[8] W. C. Skamarock, J. B. Klemp, J. Dudhia et al., "A description of the advanced research WRF version 3," Tech. Rep. NCAR/TN475+STR, 2008.

[9] X.-M. Hu, J. W. Nielsen-Gammon, and F. Zhang, "Evaluation of three planetary boundary layer schemes in the WRF model," Journal of Applied Meteorology and Climatology, vol. 49, no. 9, pp. 1831-1844, 2010.

[10] I. Jankov, W. A. Gallus Jr., M. Segal, B. Shaw, and S. E. Koch, “The impact of different WRF model physical parameterizations and their interactions on warm season MCS rainfall," Weather and Forecasting, vol. 20, no. 6, pp. 1048-1060, 2005.

[11] J. J. Ruiz, C. Saulo, and J. Nogués-Paegle, "WRF model sensitivity to choice of parameterization over South America: validation against surface variables," Monthly Weather Review, vol. 138, no. 8, pp. 3342-3355, 2010.

[12] S.-Y. Hong, Y. Noh, and J. Dudhia, "A new vertical diffusion package with an explicit treatment of entrainment processes," Monthly Weather Review, vol. 134, no. 9, pp. 2318-2341, 2006.

[13] Z. I. Janjić, “The step-mountain eta coordinate model: further developments of the convection, viscous sublayer, and turbulence closure schemes," Monthly Weather Review, vol. 122, no. 5, pp. 927-945, 1994.

[14] Z. I. Janjić, "Comments on 'development and evaluation of a convection scheme for use in climate models,' Journal of the Atmospheric Sciences, vol. 57, no. 21, p. 3686, 2000.

[15] J. S. Kain, "The Kain-Fritsch convective parameterization: an update," Journal of Applied Meteorology, vol. 43, no. 1, pp. 170181, 2004.

[16] G. A. Grell and S. R. Freitas, "A scale and aerosol aware stochastic convective parameterization for weather and air quality modeling," Atmospheric Chemistry and Physics, vol. 14, no. 10, pp. 5233-5250, 2014.

[17] S. Saha, S. Moorthi, H.-L. Pan et al., "The NCEP climate forecast system reanalysis," Bulletin of the American Meteorological Society, vol. 91, pp. 1015-1057, 2010.

[18] Y.-L. Lin, R. D. Farley, and H. D. Orville, "Bulk parameterization of the snow field in a cloud model," Journal of Climate and Applied Meteorology, vol. 22, no. 6, pp. 1065-1092, 1983.

[19] W. D. Bonner, "Climatology of the low level jet," Monthly Weather Review, vol. 96, no. 12, pp. 833-850, 1968.

[20] D. S. Wilks, Statistical Methods in the Atmospheric Sciences, Academic Press, 2nd edition, 2006.

[21] M. E. Seluchi, A. C. Saulo, M. Nicolini, and P. Satyamurty, "The Northwestern Argentinean low: a study of two typical events," Monthly Weather Review, vol. 131, no. 10, pp. 2361-2378, 2003.

[22] D.-L. Zhang and W.-Z. Zheng, "Diurnal cycles of surface winds and temperatures as simulated by five boundary layer parameterizations," Journal of Applied Meteorology, vol. 43, no. 1, pp. 157-169, 2004. 

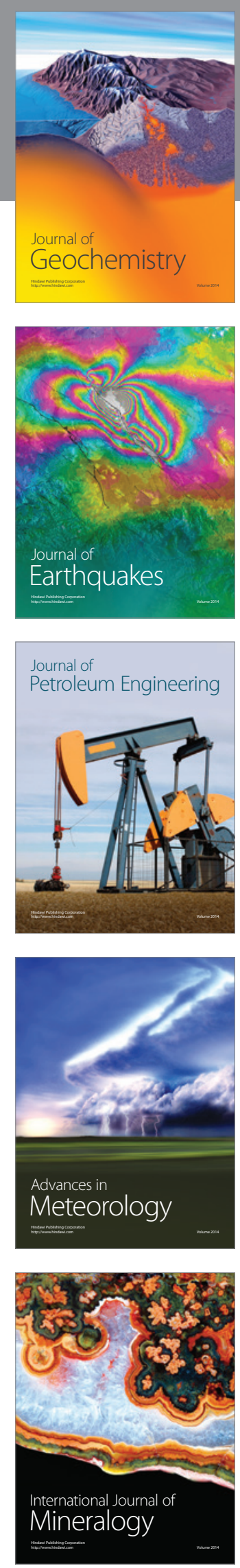
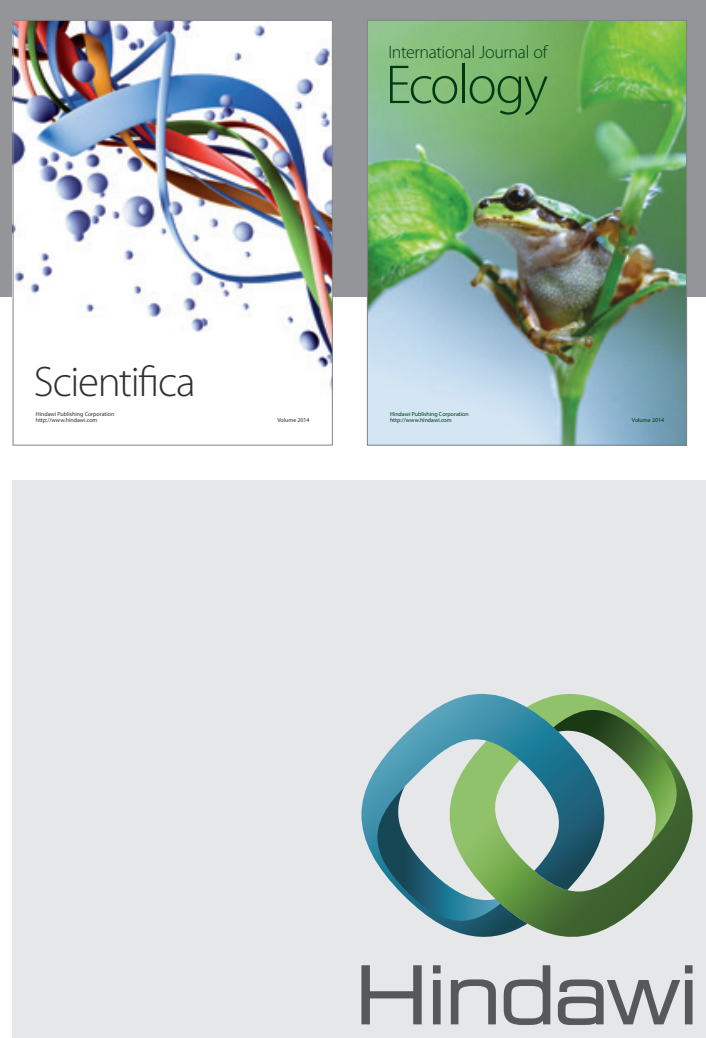

Submit your manuscripts at

http://www.hindawi.com
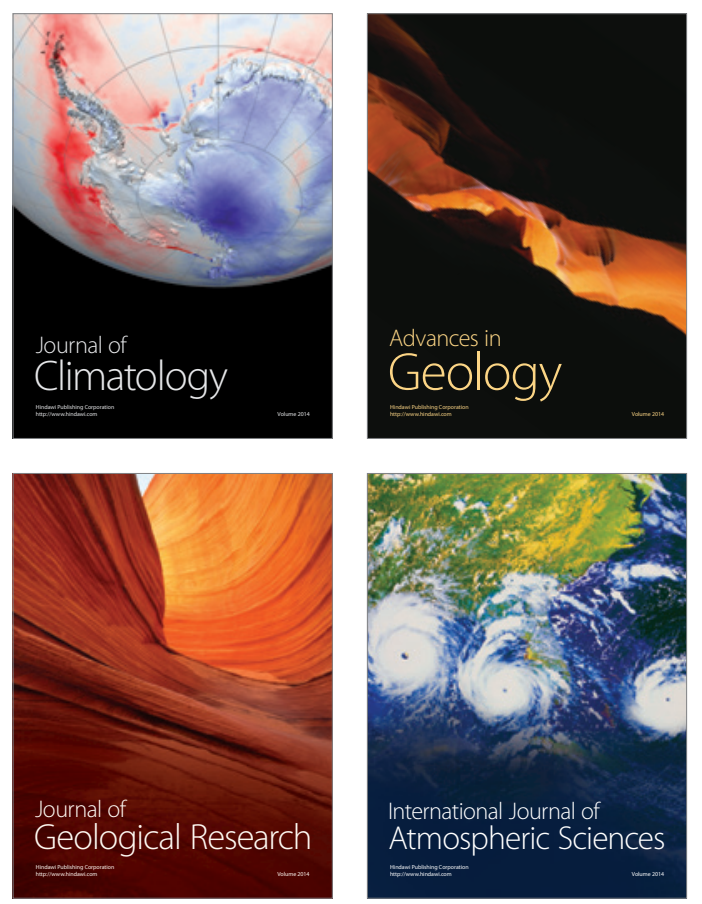

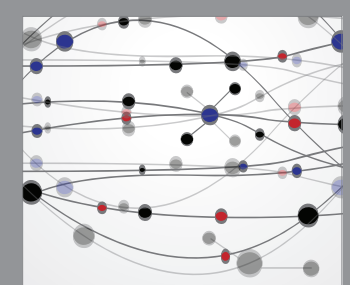

The Scientific

\section{World Journal}
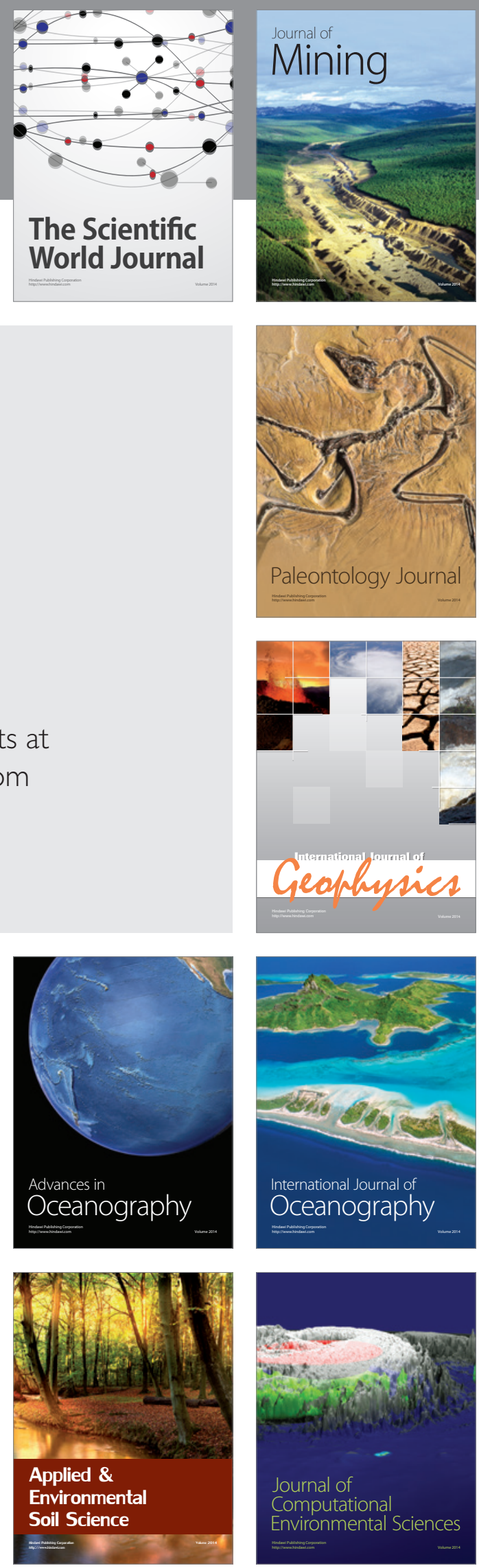